\title{
A review of $\beta$-amyloid neuroimaging in Alzheimer's disease
}

\section{Paul A. Adlard ${ }^{1 *+}$, Bob A. Tran ${ }^{2+}$, David I. Finkelstein 1, Patricia M. Desmond ${ }^{2,3}$, Leigh A. Johnston ${ }^{1,4}$, Ashley I. Bush ${ }^{1}$ and Gary F. Egan ${ }^{5,6}$}

\author{
${ }^{1}$ Division of Mental Health, The Florey Institute of Neuroscience and Mental Health, University of Melbourne, Parkville, VIC, Australia \\ ${ }^{2}$ Department of Radiology, University of Melbourne, Parkville, VIC, Australia \\ ${ }^{3}$ Department of Radiology, The Royal Melbourne Hospital, Parkville, VIC, Australia \\ ${ }^{4}$ Department of Electrical and Electronic Engineering, University of Melbourne, Parkville, VIC, Australia \\ ${ }^{5}$ Monash Biomedical Imaging, Monash University, Clayton, VIC, Australia \\ ${ }^{6}$ School of Psychology and Psychiatry, Monash University, Clayton, VIC, Australia
}

Edited by:

Stephen C. Strother, University of

Toronto, Canada

\section{Reviewed by:}

Lei Wang, Northwestern University

Feinberg School of Medicine, USA

Brian Avants, University of

Pennsylvania, USA

*Correspondence:

Paul A. Adlard, Division of Mental

Health, The Florey Institute of

Neuroscience and Mental Health,

University of Melbourne, 30 Royal

Parade, Parkville, VIC 3052, Australia

e-mail: paul.adlard@florey.edu.au

${ }^{\dagger}$ Equal first author
Alzheimer's disease (AD) is the most common cause of dementia worldwide. As advancing age is the greatest risk factor for developing $A D$, the number of those afflicted is expected to increase markedly with the aging of the world's population. The inability to definitively diagnose $A D$ until autopsy remains an impediment to establishing effective targeted treatments. Neuroimaging has enabled in vivo visualization of pathological changes in the brain associated with the disease, providing a greater understanding of its pathophysiological development and progression. However, neuroimaging biomarkers do not yet offer clear advantages over current clinical diagnostic criteria for them to be accepted into routine clinical use. Nonetheless, current insights from neuroimaging combined with the elucidation of biochemical and molecular processes in $A D$ are informing the ongoing development of new imaging techniques and their application. Much of this research has been greatly assisted by the availability of transgenic mouse models of AD. In this review we summarize the main efforts of neuroimaging in $A D$ in humans and in mouse models, with a specific focus on $\beta$-amyloid, and discuss the potential of new applications and novel approaches.

\section{Keywords: neuroimaging, Alzheimer's disease, MRI, PET, mouse models, CT, biomarkers}

\section{INTRODUCTION}

Alzheimer's disease (AD) is the most common cause of dementia worldwide, accounting for $65-75 \%$ of all cases of dementia (Bianchetti and Trabucch, 2001; Brookmeyer et al., 2011). It is characterized by neurodegenerative changes that are associated with early deficits in memory, but inexorably progresses to affect other cognitive domains. With progression of the disease, the affected individual's ability to function is eroded until all independence is lost. The annual incidence of $\mathrm{AD}$ rises markedly with age, from 53 new cases per 1000 people aged 65 to 74 , to 170 new cases per 1000 people aged 75-84, and 230 new cases per 1000 people aged over 85 (Alzheimers, 2011). Similarly its prevalence increases exponentially with age, in the United States rising from $2.32 \%$ in those aged $71-79$ years to $29.60 \%$ in those aged over 90 (Brookmeyer et al., 2011). Approximately $5 \%$ of cases occur as an inheritable trait passed on in a Mendelian manner, wherein the onset of symptoms develop relatively early in life, leading these to be termed early onset AD (EOAD) (van Gool and Eikelenboom, 2000; Rocchi et al., 2003; Minati et al., 2009). In contrast, the vast majority of cases occur sporadically as late onset $\mathrm{AD}$ (LOAD) and are multi-factorial in etiology. However, the single greatest risk factor for LOAD is age. Consequently, with increasing longevity and the overall aging of the world's growing population, the number of people with dementia is projected to increase by $234 \%$, from a currently estimated 24.3 million people to 81.1 million people by 2040 (Ferri et al., 2005). This presents immense health and economic challenges for both the present and the future.

A major impediment to the management of $\mathrm{AD}$ is the inability to definitively diagnose the disease until post-mortem examination. The initial diagnosis is presumptive, based upon clinical evaluation and neuropsychological testing and the fulfillment of certain criteria as laid out in the International Classification of Disease (10th Revision; ICD-10), the Diagnostic and Statistical Manual of Mental Disorders (Fourth Edition, Text Revision; DSM-IV-TR) and the National Institute of Neurological and Communicative Disorders and Stroke-Alzheimer's Disease and Related Disorders Association (NINCDS-ADRDA) (Honig and Mayeux, 2001; Morris, 2003; Minati et al., 2009). Application of these criteria yields a diagnostic accuracy of $80-90 \%$ when compared to the histopathological gold standard (Morris, 2003; Masters et al., 2006; Minati et al., 2009). However, a variety of disorders can lead to or mimic dementia or can co-exist with $\mathrm{AD}$, thereby worsening its progression. While conditions such as stroke, brain tumors, normal pressure hydrocephalus, infections and vitamin deficiency can be readily excluded, other causes of dementia that must be differentiated from $\mathrm{AD}$, including vascular dementia, frontotemporal dementia and dementia with Lewy bodies may present greater diagnostic challenges. Furthermore, it is now evident that patients who will develop $\mathrm{AD}$ may present as a subset of people with mild cognitive impairment (MCI). 
These patients have subjective or objective impairment in a single cognitive domain that does not impair their functional capacity. The recognition of $\mathrm{MCI}$ as a prodrome to $\mathrm{AD}$ and that neuropathology develops well in advance of any clinical symptoms gives greater impetus to developing diagnostic and prognostic biomarkers for AD.

Neuroimaging presents immense potential for developing reliable biomarkers that can be viewed in the living brain. Key neuropathological features on which the definitive diagnosis of $\mathrm{AD}$ relies, seen at post-mortem in the brains of $\mathrm{AD}$ patients, are general atrophy of the cortex, neuron and synapse loss, extracellular plaques composed of insoluble $\beta$-amyloid $(\mathrm{A} \beta)$ and intraneuronal neurofibrillary tangles (NFTs) consisting of hyperphosphorylated tau (Perl, 2010). Developments in imaging enable these features to be visualized, either directly or indirectly, providing important information on the disease processes in vivo. Early and subtle structural changes, evident as atrophy in vulnerable brain regions such as the hippocampus and entorhinal cortex, can be detected with high-resolution magnetic resonance imaging (MRI). These changes are reflected at the cellular level by alterations in metabolites detected by magnetic resonance spectroscopy (MRS). Further changes are evident with functional imaging using functional MRI (fMRI), single positron emission computed tomography (SPECT) and positron emission tomography $(\mathrm{PET})$. Functional abnormalities are surrogates of synaptic dysfunction/ loss in early $\mathrm{AD}$ and of neuronal loss with disease progression.

However, the most significant development is the ability to image the amyloid plaques, whose deposition and accumulation are widely viewed as fundamental to the pathological cascade leading to AD. Neuroimaging of plaques in humans using amyloid-labeling PET tracers and in transgenic ( $\mathrm{Tg}$ ) animal models, particularly mouse models of $\mathrm{AD}$, has greatly expanded the understanding of amyloid in the context of $\mathrm{AD}$ pathogenesis. Yet, the picture that is emerging is that significant plaque accumulation occurs prior to the earliest clinical symptoms and amyloid burden has reached a steady state by the time of clinically diagnosed AD. It may also be less important in terms of neurotoxicity than other soluble oligomeric species of $A \beta$. Understanding the true role of amyloid pathology in the pathogenesis of $\mathrm{AD}$ will provide meaningful insight into the search for effective targeted therapeutics for this disease, but it will rely as much on developing neuroimaging in animal $\mathrm{AD}$ models as the validation of techniques in humans.

In this review we will focus on $A \beta$, as it is currently the most widely studied neuroimaging biomarker for the diagnosis and monitoring of disease. Furthermore, whilst opinions are divided, a large proportion of the scientific community believe that amyloid is a primary mediator of disease pathogenesis in AD. We will briefly discuss the current understanding of the pathological mechanisms that provide the theoretical underpinnings for amyloid imaging, therein exploring the appropriateness of its use as a biomarker of AD. Finally we will examine the development amyloid imaging in Tg mouse models for application in pre-clinical and clinical research. In particular, we will attempt to highlight the technical challenges faced in validating amyloid imaging for these applications.

\section{PATHOPHYSIOLOGY OF ALZHEIMER'S DISEASE CENTRAL ROLE OF $\beta$-AMYLOID IN ALZHEIMER'S DISEASE}

Central to the pathogenesis of $\mathrm{AD}$ is the $\mathrm{A} \beta$ protein, produced from the cleavage of the amyloid precursor protein (APP). Over $80 \%$ of cases of EOAD are accounted for by mutations in either the gene for APP or one of two other proteins presenilin-1 (PS1) and presenilin-2 (PS2), which form part of the $\gamma$-secretase complex (Rocchi et al., 2003). These mutations lead to an accelerated production of $A \beta$ that exceeds its clearance mechanisms and subsequently results in its accumulation in the brain. In contrast, LOAD develops from impaired clearance of $A \beta$ due to various factors (Zetzsche et al., 2010).

Cleavage of APP occurs sequentially by the action of either $\alpha$ secretase or $\beta$-secretase (BACE-1) and $\gamma$-secretase (Masters et al., 2006; Murphy and LeVine, 2010). Whilst the majority of APP is processed by $\alpha$-secretase to result in non-amyloidogenic cleavage products (Masters et al., 2006; Murphy and LeVine, 2010), a proportion is cleaved by $\beta$-secretase and $\gamma$-secretase to result in the formation of $A \beta$ peptides (Murphy and LeVine, 2010). The predominant forms of $A \beta$ produced are $A \beta_{40}$ and $A \beta_{42}$, of which the former is more common. However, the latter has a greater propensity for aggregating into oligomers and fibrils and is believed to be the more toxic product (Ballard et al., 2011). Degradation of $A \beta$ has been attributed to a number of mechanisms. Extracellular enzymatic degradation may be carried out by neprilysin and insulin degrading enzyme, while intracellular lysosomal degradation may also play a role (Murphy and LeVine, 2010). In addition, the activity of microglia may also play an important role in clearance of both soluble $A \beta$ and its fibrillar aggregates (Agostinho et al., 2010; Lee and Landreth, 2010).

The mechanisms leading to $A \beta$ aggregation are not fully understood but a number of factors may be involved. It is likely that protein folding plays a crucial role in amyloidogenesis, as proteins seek to attain a quaternary structure that has a minimum energy and hence most stable conformation (Bharadwaj et al., 2009). An alternative but stable "misfolded" state may make $\mathrm{A} \beta$ prone to aggregation and mutations associated with FAD may predispose to misfolding (Bharadwaj et al., 2009). Similar to prion diseases, this abnormal aggregation and precipitation could be the cause of amyloidosis in $\mathrm{AD}$. $\mathrm{A} \beta$ aggregation may be a consequence of interactions with other factors such as the metals zinc and copper, which are dysregulated in the AD brain (Bush, 2008; Kawahara, 2010).

How $A \beta$ aggregates exert their neurotoxic effects is still unclear. Amyloid has been shown to be directly toxic to neuronal cell cultures (Golde et al., 2006). Evidence suggests a number of pathways by which $\mathrm{A} \beta$ acts. Chief among these is oxidative stress and inflammation, which have an established role in the biology of aging, and calcium dyshomeostasis (Reddy, 2009; Kawahara, 2010). In AD, these pathological processes have the early consequences of synaptic dysfunction and culminate later in neuronal loss. Amyloid burden, however, correlates poorly with disease severity, suggesting a lesser role for insoluble $A \beta$ fibrils, while soluble $A \beta$ oligomers appear to play the major part in neurotoxicity (Minati et al., 2009). 


\section{MECHANISMS OF AMYLOID- $\beta$ PATHOGENESIS}

Evidence strongly suggests oxidative stress has an early and important role in the pathogenesis of AD (Maynard et al., 2005; Agostinho et al., 2010; Muller et al., 2010; Santos et al., 2010). Redox reactions occurring during normal cellular respiration produce reactive oxygen species (ROS) such as superoxide anion, hydroxyl radical and hydrogen peroxide. ROS interact with and alter cellular components, including nucleic acids, lipids and proteins, causing damage to important cellular structures and impairing their functions. Molecular mechanisms have evolved to minimize and repair oxidative damage but they may be overwhelmed, tipping the balance toward oxidative stress. The consequence of accumulated oxidative damage is a molecular cascade resulting in cellular dysfunction and ultimately, the triggering of pathways leading to cell death (Sultana et al., 2009).

In $\mathrm{AD}$, accelerated oxidative stress is likely driven by $\mathrm{A} \beta$ pathology in a number of ways. One mechanism is by interactions with and the dysregulation of important biological metals. Another is by impairment of mitochondria, the organelles in which cellular respiration resides and the main source of endogenous ROS in cells (Casadesus et al., 2004; Agostinho et al., 2010). Increased APP in mitochondrial membranes may be one cause of mitochondrial dysfunction in neurons (Kawahara, 2010). Furthermore, $\mathrm{A} \beta$ may also disrupt mitochondrial membrane function by inserting into it as oligomers, creating calciumpermeable channels (Reddy, 2009; Kawahara, 2010). This affects the flux of calcium across the membrane with resultant mitochondrial structural and functional damage (Reddy, 2009). A $\beta$ oligomers are also incorporated into neuronal membranes, leading to a wider dysregulation of calcium homeostasis in the neuron (Kawahara, 2010). Disruption of calcium homeostasis affects cellular function and can trigger apoptotic pathways of cellular death. Therefore, $A \beta$-induced calcium dyshomeostasis may act synergistically with oxidative stress to cause neuronal dysfunction and death.

Both the increasing presence of $A \beta$ aggregates and the release of substances by dying neurons incite neuroinflammation, which is an early event in AD (Agostinho et al., 2010; Glass et al., 2010; Lee and Landreth, 2010). Inflammatory mediators such as cytokines and activated complement components are elevated in vulnerable brain regions in AD (Agostinho et al., 2010; Lee and Landreth, 2010). Furthermore, the presence of activated microglia and astrogliosis around senile plaques support the role of inflammation (Agostinho et al., 2010; Glass et al., 2010; Lee and Landreth, 2010). Microglia and astrocytes may have neuroprotective functions by their scavenging and clearance of $A \beta$ aggregates (Agostinho et al., 2010; Lee and Landreth, 2010). However, they may also mediate neurotoxic effects by release of pro-inflammatory cytokines, chemokines, ROS and complement proteins (Lee and Landreth, 2010). Furthermore, APP mRNA is upregulated by IL-1, an inflammation cytokine, further promoting amyloidosis and reinforcing a self-perpetuating cycle (Rogers and Lahiri, 2004).

How $\mathrm{A} \beta$ pathology is related to tau pathology remains unclear. However, there is growing evidence to support the direct or indirect interaction of $\mathrm{A} \beta$ with tau to accelerate NFT formation. It is likely that $A \beta$ pathology lies upstream of tau pathology, as genetic mutations leading to elevated $A \beta$ levels or aggregation also leads to NFT formation while no reciprocal relationship with tau accumulation has been found (Blurton-Jones and Laferla, 2006). Phosphorylation of tau at various sites promotes their aggregation and NFT formation while $A \beta$ is shown to activate several tau kinases, providing a straight forward mechanism for induction of NFT formation by A $\beta$ (Blurton-Jones and Laferla, 2006; Mi and Johnson, 2006). Other suggested links are: A $\beta$-induced inflammation with resulting induction and enhancement of tau phosphorylation by inflammatory cytokines; $A \beta$-induced proteasomal impairment of tau degradation; and dysregulation of axonal transport with possible bidirectional effects, leading to increases in $\mathrm{A} \beta$ as well as tau (Blurton-Jones and Laferla, 2006).

Accumulation of $A \beta$ and abnormal tau pathology exerts an effect on synapses, affecting their density and function and consequently the function of neuronal circuits within the brain (Selkoe, 2008; Arendt, 2009; Palop and Mucke, 2010). Histopathological examination of $\mathrm{AD}$ brain tissue from patients within 2-4 years after clinical onset of $\mathrm{AD}$ reveals significant reductions in postsynaptic dendritic spine density. These changes are most marked in the hippocampus and least prominent in the occipital cortex, exhibiting differences in the regional distribution of synaptic alterations that matches the pattern outlined in the Braak and Braak staging system (Arendt, 2009). Furthermore, this reduction in synaptic density is already evident in patients with MCI (Arendt, 2009). A $\beta$ oligomers, both synthetic and naturally occurring, have been shown to mediate synaptic dysfunction, impairing long-term potentiation as well as enhancing longterm depression (Selkoe, 2008; Shankar et al., 2008; Sultana et al., 2009; Palop and Mucke, 2010). Studies have shown elevated $\mathrm{A} \beta$ decreases excitatory glutamatergic synaptic transmission by reductions in post-synaptic $\alpha$-amino-3-hydroxy-5-methyl4 -isoxazolepropionic acid receptor (AMPA) receptors and $N$ methyl-D-aspartate (NMDA) receptors (Palop and Mucke, 2010). Furthermore, accumulation of abnormally phosphorylated tau species within synaptic terminals in AD brains and APP transgenic mice has been reported, suggesting a link between tau and synaptic pathology (Arendt, 2009). Synaptic dysfunction consequently leads to alterations in brain activity and connectivity, evident as regional alterations in activity on functional studies (Bokde et al., 2009).

In summary, these data support a primary role for $A \beta$ in the pathogenesis of $\mathrm{AD}$ (although clearly there are other aspects that are also very important). As such, the ability to detect $A \beta$ in the brain of living individuals has long been heralded as a key to allow the earliest detection of $\mathrm{AD}$, with the subsequent benefit of expedited treatment and the hope of extending the number of disease free years. There are several important caveats to this however. Firstly, A $\beta$ accumulates in the brains of normal individuals. In the earliest stages this appears to correlate with subjective cognitive complaints, although not with objective measurements of memory and executive function (Amariglio et al., 2012). This may, however, represent an early indicator for the subsequent development of $\mathrm{AD}$. The time frame between the first detection of $\mathrm{A} \beta$ by neuroimaging and the clinical manifestation of $\mathrm{AD}$ may also be quite long, as $\mathrm{A} \beta$ accumulates at quite a slow rate (Villemagne et al., 2013). Furthermore, whilst A $\beta$ generally 
increases continuously from the levels found in younger healthy controls to those found in $\mathrm{AD}$, it does not do so in a linear fashion, with rates of deposition slowing in more advanced stages of disease (Villemagne et al., 2013). That being said, understanding the natural history of $A \beta$ formation and deposition will provide a greater understanding of the overall dynamics of the potential progression from healthy control, through MCI (individuals in this group have a transition rate to $\mathrm{AD}$ of approximately $30.5 \%$ Ellis et al., 2014) and into AD. This will ultimately provide a better prognostic indication for the individual with a given $\mathrm{A} \beta$ burden. In addition, such data will facilitate better controlled clinical studies by allowing $A ß$ burden to be used as an intake/cutoff criteria for inclusion in drug studies.

Another important caveat is in regards to whether the level of $A \beta$ accumulation, as observed through neuroimaging methodologies, is a good correlate of cognitive function-this remains a contentious issue, with the majority of studies suggesting that it is a poor marker of disease severity. However, a recent study demonstrated, for the first time, that there was an association between the rate of $\mathrm{A} \beta$ deposition and memory decline in a cohort of $\mathrm{AD}$ patients (Villemagne et al., 2013). These findings arose out of the Australian Imaging, Biomarkers and Lifestyle study, which is a multi-year prospective study of 1112 individuals with either $\mathrm{AD}$, MCI or no pathology (age-matched healthy controls), and perhaps demonstrates the need for such large, well-controlled studies in order to discern correlations between $\mathrm{A} \beta$ burden and cognitive function. Thus, there are several important outcomes, both for the individual and for the community, that serve as important rationales for continuing neuroimaging initiatives in $\mathrm{AD}$.

\section{NEUROIMAGING IN ALZHEIMER'S DISEASE}

The current clinical role of neuroimaging in $\mathrm{AD}$ is the exclusion of any other disease pathology that may be causative of cognitive decline (Ferreira and Busatto, 2011; McKhann et al., 2011). These include cerebrovascular diseases, tumor, subdural haematoma or other causes of dementia, including dementia with Lewy bodies and frontotemporal dementia (Lee et al., 2003; Small et al., 2008; Mistur et al., 2009). Additionally, imaging may reveal cerebral atrophy evidenced by ventricular and sulcal enlargement, non-specific signs which can only support the diagnosis of AD as they are also observed in normal aging and other dementias. The two imaging modalities in routine use are computed tomography (CT) and MRI. Of the two, MRI is preferred due to its far superior soft tissue resolution and hence its ability to provide detailed structural information (Ferreira and Busatto, 2011). Nonetheless, CT has limited utility in the diagnostic work up, particularly where MRI is contraindicated (Ferreira and Busatto, 2011).

Recently, with advances in imaging technology, studies using MRI and PET neuroimaging of AD have identified a number of potential biomarkers (Ferreira and Busatto, 2011). However, these biomarkers have yet to gain acceptance as a diagnostic criteria (McKhann et al., 2011). Consequently their main application is in the area of research, with the aim of furthering understanding into the pathological processes of $\mathrm{AD}$ and also of improving their reliability for routine clinical use. With continuing advances, the potential of imaging biomarkers draws closer to realization.

\section{MAGNETIC RESONANCE IMAGING}

The high resolution provided by MRI has made it especially useful in studying the morphological details of the AD brain in situ. Analyses in quantitative structural studies of brain atrophy are commonly applied to gray matter changes in $\mathrm{T}_{1}$-weighted images and have been either cross-sectional or longitudinal (Vemuri and Jack, 2010). Cross-sectional volumetric analysis of medial temporal lobe (MTL) structures can be done qualitatively by visual assessment or quantitatively by analysis of regions of interest either using manual tracing and measurement or automated techniques (Vemuri and Jack, 2010). Voxel-based analysis has also been applied for comparisons between an $\mathrm{AD}$ group and a control group to detect subtle differences (Glodzik-Sobanska et al., 2005; Vemuri and Jack, 2010). Longitudinal methods of analysis include global atrophy quantification by analysis of brain boundary shifts, and tensor-based morphometry, a 3-dimensional voxel-based method (Glodzik-Sobanska et al., 2005; Coimbra et al., 2006; Vemuri and Jack, 2010). While brain atrophy is not specific to AD, studies have revealed atrophy of the MTL is well correlated with changes in cognition and disease progression (Coimbra et al., 2006; Frisoni et al., 2010; Vemuri and Jack, 2010). In particular, atrophy of the hippocampus and entorhinal cortex is of particular value as a biomarker due to their involvement in the earliest stage of disease and strong correlation with NFT pathology (GlodzikSobanska et al., 2005; Ramani et al., 2006; Vemuri and Jack, 2010). Hippocampal volume is reduced in MCI patients by $10-15 \%$ while in mild and moderate $\mathrm{AD}$ it is reduced by $15-30 \%$ and 30-40\% respectively (Lehericy et al., 2007; Frisoni et al., 2010). The rate of atrophy is also predictive of progression, being 4-6\% per year in $\mathrm{MCI} / \mathrm{AD}$ patients compared to $1-2 \%$ in age-matched controls (Coimbra et al., 2006). As will be discussed later, MR imaging has been successfully applied to animal models of AD, and in some cases has provided unique observations of potential relevance to the human condition. Volumetric losses present outside of forebrain structures, for example, have been reported to predict sites of future amyloid formation (Badea et al., 2010).

Structural studies have also utilized other MR imaging techniques to image pathological alterations in both gray and white matter. Diffusion weighted imaging (DWI) with apparent diffusion coefficient (ADC) mapping and diffusion tensor imaging (DTI) has been used to investigate the white matter changes in areas such as the temporal lobe, hippocampus and corpus callosum (Ramani et al., 2006; Small et al., 2008; Stebbins and Murphy, 2009). In particular, DTI is capable of assessing microstructural and connective changes in the hippocampus and its related structures, arising from neuronal loss and axonal degeneration (Yakushev et al., 2011a,b; Hattori et al., 2012). Alternatively, magnetization transfer imaging (MTI) is able to detect structural damage as a reduction in the magnetization transfer rate (MTR) reflects decreased tissue homogeneity from pathological changes such as neuronal loss and gliosis in gray matter, and demyelination and axonal loss in white matter (Glodzik-Sobanska et al., 2005; Ramani et al., 2006). Decreased MTR is found in both white and gray matter in $\mathrm{AD}$ patients and has been reported in the hippocampus in very mild AD (Ramani et al., 2006).

At a molecular level, cellular changes associated with neuronal pathology can be studied using MRS. The most commonly 
studied metabolites in MRS experiments of the brains of $\mathrm{AD}$ patients are $\mathrm{N}$-acetyl-aspartate (NAA), choline and creatinine, which are associated with neuronal function, membrane turnover and energy consumption respectively (Lee et al., 2003; Coimbra et al., 2006; Scott et al., 2011). NAA has been found to be decreased in $\mathrm{AD}$, consistent with neuronal damage (Coimbra et al., 2006). As the levels of choline or creatinine are relatively unchanged, the ratio of NAA to these metabolites may be a useful biomarker for AD (Lee et al., 2003; Coimbra et al., 2006). Other metabolites are also being currently investigated for their value in early diagnosis. Examples include myo-inositol (mIns), which may be a marker of glial activation and hence neuroinflammation, lactate for monitoring anaerobic metabolism indicative of hypoxia and ischaemia, and glutamine/glutamate for evaluating regulation of neurotransmission (Ashford et al., 2011).

While neuronal loss is an obvious endpoint resulting from the progression of AD pathology, it is now evident that this is preceded by neuronal dysfunction. This can be measured by changes in cellular metabolic rate, which on a regional level can be visualized in vivo as changes in the metabolic demand reflected by decreased vascular perfusion and oxygen consumption (Wu and Small, 2006). Consequently there are a number of functional MRI ( $\mathrm{MMRI}$ ) studies that have assessed the consequence of neuropathology in terms of neuronal activity and connectivity. These studies are based either on changes in cerebral blood flow and cerebral blood volume or changes revealed by the blood oxygen level dependent (BOLD) effect (Wu and Small, 2006; Brickman et al., 2009; Beckmann, 2011). Estimation of changes in cerebral blood flow and cerebral blood volume involves either the injection of intravenous paramagnetic contrast, such as gadolinium or superparamagnetic iron oxide nanoparticles or the technique of arterial spin labeling (ASL) (Wu and Small, 2006; Brickman et al., 2009; Beckmann, 2011). In contrast, the BOLD effect utilizes the paramagnetic properties of deoxyhaemoglobin. Activation therefore increases CBF out of keeping to metabolic needs. This leads to an increase in oxyhaemoglobin and a relative decrease in deoxyhaemoglobin which leads to a relative increase in signal on T2* weighted imaging (Wu and Small, 2006; Brickman et al., 2009; Beckmann, 2011). FMRI studies have identified abnormalities in activity associated with a variety of cognitive tasks in a number of regions (Dickerson and Sperling, 2009; Sperling et al., 2010). Compared to healthy older controls, AD patients are reported to exhibit decreased hippocampal and parahippocampus activity, as well as decreased activity in the frontal and prefrontal regions (Sperling et al., 2010). Also, AD patients show less coordinated activity in the default mode network (DMN), a functional network consisting of the posterior cingulate, hippocampus, lateral inferior parietal and medial frontal lobes, that is most active at rest and reduces in activity during the performance of cognitive tasks (Small et al., 2008; Bokde et al., 2009; Dickerson and Sperling, 2009; Sperling et al., 2010).

Though imaging functional and structural consequences has provided many insights into $\mathrm{AD}$, it is the potential to visualize molecular pathology that has stirred the imagination in MRI research. Since the first observations by Benveniste et al. (1999) that hypointensities on $\mathrm{T}_{2}^{*}$-weighted MRI of ex vivo $\mathrm{AD}$ brains corresponded to neuritic plaques there has been great interest in the use of MRI in AD. Despite contrary findings by Dhenain et al. (2002), research into the development of MRI techniques to improve visualization and quantification of $\mathrm{A} \beta$ deposits in vivo has been ongoing. However, much of the imaging of human AD brains has been done ex vivo (Benveniste et al., 1999; Dhenain et al., 2002; House et al., 2007, 2008; Schrag et al., 2010; Nabuurs et al., 2011). Analyses of amyloid plaques suggest their inherent contrast on $\mathrm{T}_{2}^{*}$-weighted imaging is attributable to increased iron content relative to surrounding tissues (Benveniste et al., 1999; Nakada et al., 2008; Nabuurs et al., 2011). Similar to other neurodegenerative diseases such as Parkinson's disease, iron dyshomeostasis has an important and early role in the disease process (Bartzokis et al., 2004). Abnormal Fe accumulation in the $\mathrm{AD}$ brain is evident from MR measurements of transverse relation rates $\left(R_{2}\right)$ in post-mortem studies (House et al., 2007, 2008). However, while these studies found a correlation between iron and $\mathrm{R}_{2}$, amyloid plaque density was not correlated with iron concentrations. Nonetheless, plaque-associated iron can potentially be harnessed to enhance their contrast by susceptibility-weighted imaging (SWI) in living patients (Nakada et al., 2008).

Further work is still needed to validate the clinical use of in vivo functional and plaque MRI in living patients with $\mathrm{AD}$. For plaque imaging, one need is for improvement in the time efficiency of the scanning while achieving the required contrast and resolution. Another problem lies in the difficulty in correlating this imaging with histology. This is partly due to artifacts arising from other sources of iron (blood vessels, micro-hemorrhages) or as a result of head motion during long scanning times (Versluis et al., 2010). Because of this, there have been very few in vivo studies in living subjects (Nakada et al., 2008; Versluis et al., 2010). There are also limitations related to functional imaging with ASL and BOLD. Firstly, there is potential bias from the use of external stimuli and differences in cognitive task performance, which requires carefully constructed experimental paradigms for study validity. Secondly, high temporal resolution in the order of seconds is needed to capture transient evoked changes, making this technique very sensitive to head motion and compromising spatial resolution. Thirdly, disease related changes to brain structure make changes in responses difficult to interpret. Finally, fMRI produces relative rather than quantitative measures of brain activity, which can be problematic when applied to diagnostic or longitudinal monitoring purposes (Brickman et al., 2009; Dickerson and Sperling, 2009).

\section{RADIONUCLIDE IMAGING}

Early radionuclide imaging in $\mathrm{AD}$ made use of PET and SPECT to evaluate functional alterations in the brain (Mosconi et al., 2010). SPECT analysis using Tc-99-labeled hexamethylpropyleneamine oxime (Tc-99-HMPAO) is able to show a global reduction in cerebral blood flow along with focal changes in terms of temporoparietal hypoperfusion (Lee et al., 2003; Coimbra et al., 2006). However, the predictive accuracy of SPECT for diagnosing $\mathrm{AD}$ is variable but generally found to be less than PET, making it of limited clinical use (Lee et al., 2003; Coimbra et al., 2006). The most common PET tracer used in functional studies is 2$\left[{ }^{18}\right.$ Flfluoro-2-Deoxy-D-glucose (FDG). FGD PET studies show a specific regional pattern of cerebral glucose metabolism in $\mathrm{AD}$ 
compared to controls. Deficits are consistently observed in the temporoparietal, MTL and posterior cingulate cortices, and later in the frontal cortex as the disease progresses (Lee et al., 2003; Coimbra et al., 2006; Mosconi et al., 2010). Notably the primary sensory, motor and visual cortices, cerebellum, striatum and basal ganglia are preserved (Lee et al., 2003; Mosconi et al., 2010). This pattern can be used to distinguish $\mathrm{AD}$ from other forms of dementia such as FTD and DWLB, and from cerebrovascular disease (Mosconi et al., 2010). Evidence also suggests that these metabolic reductions precede clinical symptoms as well as structural brain changes in predisposed people (Mistur et al., 2009; Mosconi et al., 2010). Thus, it is suggested that FDG PET may be useful in $\mathrm{AD}$ prognostication and as an adjunct to clinical assessment for diagnosis (Lee et al., 2003; Mistur et al., 2009; Mosconi et al., 2010).

More recently the development of peptide and antibody probes has extended the use of PET beyond functional analysis to allow direct imaging of amyloid in vivo. Many of the molecular probes are derivatives of histological dyes such as Congo Red, thioflavin $\mathrm{S}$ and $\mathrm{T}$, Acridine Orange and Chrysamine-G (Coimbra et al., 2006; Fodero-Tavoletti et al., 2009) or other molecules such as styrylbenzene. Two of the most extensively used ligands are $\left[{ }^{11} \mathrm{C}\right] 2-\left(4^{\prime}-\right.$ methylaminophenyl $)$ 6-hydroxybenzothiazole (Pittsburgh Compound B or PIB) (Small et al., 2008; Fodero-Tavoletti et al., 2009; Mosconi et al., 2010) and 2-(1-\{6-[2-[ $\left.{ }^{18} \mathrm{~F}\right]$-fluoroethyl)(methyl)amino]-2naphthyl $\}$ ethylidene) malononitrile ( $\left.\left[{ }^{18} \mathrm{~F}\right]-F D D N P\right)$ (Small et al., 2008; Fodero-Tavoletti et al., 2009; Mosconi et al., 2010). [ $\left.{ }^{18} \mathrm{~F}\right]-$ FDDNP was the first ligand successfully employed in humans (Rabinovici and Jagust, 2009). However, it binds both diffuse and dense-core amyloid along with tau (Coimbra et al., 2006; Mistur et al., 2009; Rabinovici and Jagust, 2009), complicating its interpretation and limiting its ability to differentiate AD from FTD and other tauopathies.

PIB on the other hand binds with high affinity and specificity to fibrillar A $\beta$ (Coimbra et al., 2006; Fodero-Tavoletti et al., 2009; Mosconi et al., 2010) and its in vivo PET signal correlates strongly with in vitro measures of $\mathrm{A} \beta$ burden in post-mortem $\mathrm{AD}$ brains (Rabinovici and Jagust, 2009). Studies have demonstrated elevated retention of $\mathrm{PIB}$ in the brains of $\mathrm{AD}$ patients compared to healthy controls (Coimbra et al., 2006; Small et al., 2008; Mosconi et al., 2010). Significant PIB retention is found in $90 \%$ of clinically diagnosed $\mathrm{AD}$ patients and approximately $60 \%$ of individuals with MCI and 25-30\% of normal elderly (Fodero-Tavoletti et al., 2009; Mosconi et al., 2010). The regional distribution of high retention in $\mathrm{AD}$ brains is in areas known to have high amyloid deposition, most prominently the frontal cortex, parietal cortex, lateral temporal cortex, posterior cingulated cortex/precuneus, thalamus and striatum (Coimbra et al., 2006; Rabinovici and Jagust, 2009; Mosconi et al., 2010). This pattern of distribution allows differentiation of AD from FTD and Parkinson's disease (Mosconi et al., 2010), though significant retention and a similar pattern can also seen in DWLB (Fodero-Tavoletti et al., 2009; Mosconi et al., 2010; Villemagne and Rowe, 2011). Imaging with PIB has also provided important insights into the relationship between amyloid burden and various markers of $\mathrm{AD}$, such as cognitive decline (Rowe et al., 2010), functional alterations (Hedden et al., 2009; Rabinovici and Jagust, 2009; Shin et al., 2010, 2011; Mormino et al., 2012) and regional brain atrophy (Jack et al., 2008; Chetelat et al., 2010; Rowe et al., 2010).

A distinct disadvantage of PIB imaging is the short half-life of ${ }^{11} \mathrm{C}$, which is around $20 \mathrm{~min}$. This necessitates the existence of a cyclotron in close proximity for production of the radioisotope label. Labeling of PET imaging probes with ${ }^{18} \mathrm{~F}$, a radioisotope with a half-life of 110 min removes this limitation (Mistur et al., 2009). This approach has yielded a number of potential radiotracers, such as the 3 '-fluoro-derivative of PIB, $\left[{ }^{18} \mathrm{~F}\right]-3^{\prime}$-FPIB (flutemetamol), and the strylpyridine and stilbene derivatives $\left[{ }^{18} \mathrm{~F}\right]-\mathrm{AV}-45$ (florbetapir) and $\left[{ }^{18} \mathrm{~F}\right]-\mathrm{AV}-1$ (florbetaben) (Herholz and Ebmeier, 2011; Vallabhajosula, 2011). Not surprisingly, $\left[{ }^{18} \mathrm{~F}\right]$ $3^{\prime}$-FPIB has near identical binding properties to PIB and performs similarly in clinical studies (Vallabhajosula, 2011). $\left[{ }^{18} \mathrm{~F}\right]-$ $\mathrm{AV}-45$ and $\left[{ }^{18} \mathrm{~F}\right]-\mathrm{AV}-1$ also exhibit high affinity binding to fibrillar amyloid similar to PIB (Herholz and Ebmeier, 2011; Vallabhajosula, 2011). Ongoing development in amyloid-specific PET ligands will improve their utility and widen their accessibility for both research purposes and potentially routine clinical applications.

\section{ADVANCES FROM PRE-CLINICAL NEUROIMAGING IN MOUSE MODELS MODELS OF ALZHEIMER'S DISEASE}

Animal models of AD have been extensively utilized in the investigation of the disease. The best model is the aged monkey, such as the Caribbean vervet monkey, lemur, cotton-top tamarin, rhesus monkey and squirrel monkey (Philipson et al., 2010). However, the time and cost involved makes primate models prohibitive for routine use in research (Crews et al., 2010). There have been a variety of other models including: rats, rabbits, dogs, the fruit fly Drosophila melanogaster, the nematode Caenorhabditis elegans and two types of fish, the sea lamprey, Petromyzon marinus and the zebrafish (Götz et al., 2004; Götz and Götz, 2009; Crews et al., 2010; Murphy and LeVine, 2010; Philipson et al., 2010). However, the overwhelming majority of research has been carried out in transgenic mouse models, which confer advantages in terms of time and cost-effectiveness. At the same time they allow the detailed analysis of pathological mechanisms at molecular, anatomical and cognitive/behavioral levels.

Early models expressing human $A \beta$ fragments, wild type human APP, or fusion proteins containing the C-terminal fragment of wild type APP or $A \beta_{42}$ showed little or sparse AD-like neuropathology or atypical $A \beta$ deposition (Philipson et al., 2010). However, with identification of EOAD-associated APP mutations, transgenic mouse models were developed expressing high levels of human APP incorporating these mutations. The first APP transgenic mouse was the PDAPP mouse, which incorporated one of the earliest APP mutations identified, the Indiana mutation (V717F) (Philipson et al., 2010; Wisniewski and Sigurdsson, 2010). PDAPP mice develop both senile and diffuse plaques from 9 months of age and showed deficits in learning and memory (Elder et al., 2010; Philipson et al., 2010). This was followed by what is the most commonly used APP transgenic model, the Tg2576 mouse harboring human APP with the Swedish mutation (KM670/671NL) under the control of the prion promoter. 
These mice have five-fold overexpression of human APP, develop $\mathrm{A} \beta$ deposits from 9 to 12 months of age and exhibit substantial cerebral amyloid angiopathy (CAA) (Crews et al., 2010; Philipson et al., 2010; Wisniewski and Sigurdsson, 2010). Other engineered models have incorporated other mutations such as the London (V717I), Arctic (E693G), Iowa (D694N), Flemish (A692G), or Dutch (E693Q) mutation, resulting in various patterns of $A \beta$ deposition and pathology. For example, mice expressing the Dutch and Iowa mutations have a propensity for CAA and diffuse $A \beta$ deposits. However, in most of these transgenic mice there is a lack of neuronal loss. This lead to the development of models expressing combinations of different APP mutations in an attempt to enhance neuronal toxicity, such as the APP23 mouse which harbors both the Swedish and London mutations (Crews et al., 2010; Elder et al., 2010; Philipson et al., 2010; Wisniewski and Sigurdsson, 2010).

Following the identification of presenilin mutations, these were similarly incorporated into mouse models. However, singly transgenic mice with either PS1 or PS2 did not develop plaques despite consistently showing elevated levels of $A \beta_{42}$. Subsequent cross breeding of APP and PS transgenic mice, as well as introduction of knockin PS1 mutations in APP mutated mice produced doubly transgenic models. Different combinations of APP mutations with PS1 or PS2 mutations have produced a variety of APP/PS1 double transgenic models. One example is the PSAPP model, produced by crossing PS1 M146L or M146V mutant mice with Tg2576 mice. These mice showed markedly accelerated amyloid deposition from an earlier age and increased overall plaque numbers, as well as early cognitive deficits (Crews et al., 2010; Elder et al., 2010; Philipson et al., 2010).

These models of AD have been used to explore various aspects of its pathophysiology, ranging from $\mathrm{A} \beta$ metabolism and amyloid deposition to the effect of APOE genotype as well as tau and NFT pathology (Götz et al., 2004). However, while the amyloid deposits in mouse models closely resemble human amyloid, not all aspects of AD pathology are reproduced in transgenic mice. Except for triple transgenic mice, which incorporate tau mutation, the mice lack NFTs. Another difference is that amyloid deposition is not associated with significant neuronal loss, apart from when multiple mutations in either or both of APP and PS1 in double transgenic mice were introduced (Golde et al., 2006; Fiala, 2007; Elder et al., 2010).

Despite these limitations mouse models play an important role in ongoing research in $\mathrm{AD}$, providing valuable insights into pathophysiology. Furthermore, through the knowledge gained these models are facilitating the search for new therapies and improved methods for diagnosis.

\section{MAGNETIC RESONANCE IMAGING IN MOUSE MODELS}

Research into the imaging of $\mathrm{AD}$ pathology in transgenic $\mathrm{AD}$ mouse models using MR has followed two general strategies. One is the indirect measure of $\mathrm{AD}$ pathology reflected in changes in relaxometry. The other is to develop techniques to utilize or enhance the inherent contrast of amyloid plaques so as to directly visualize them. Relaxometry studies involve statistical analysis of measures of longitudinal and transverse relaxation values in regions of interest for differences between $\mathrm{AD}$ transgenic mouse brains and age-matched non-transgenic mouse brains that could be attributed to $A \beta$ deposition. The advantage of this method is, being based on ROIs, it is less reliant on resolution (Muskulus et al., 2009). In direct imaging of plaques the very small size of many plaques requires a resolution with appropriately small voxel dimensions. This increases scanning time and reduces the signalto-noise ratio, impeding the routine application of MR amyloid imaging in in vivo research. Furthermore, the mechanisms underpinning signal changes are not yet fully understood (Braakman et al., 2009; Chamberlain et al., 2011). Consequently there is a great deal of ongoing research effort into methods for improving contrast and resolution in MR imaging and correlating this imaging to the biophysics and physiology of $\mathrm{AD}$ pathology.

Helpern et al. (2004) were the first to acquire parametric maps of $T_{2}$ and $T_{1}$ relaxation times and proton density to analyse changes in measured values that may reflect altered cellular physiology secondary to AD pathology (refer to Table 1). Of these three measures they found only $\mathrm{T}_{2}$ was reduced in the hippocampus, cingulate and retrosplenial cortex of APP/PS1 mice compared to PS1 and non-Tg mice, while $\mathrm{T}_{1}$ and proton density were unchanged between the genotypes. The correlation between reduction in $\mathrm{T}_{2}$ relaxation time and increased amyloid burden was later confirmed by other studies (Falangola et al., 2005a; Vanhoutte et al., 2005; Borthakur et al., 2006; Braakman et al., 2006; El Tannir El Tayara et al., 2006; El Tayara Nel et al., 2007). Apart from confirming $\mathrm{T}_{2}$ changes in APP/PS1 mice, Falangola et al. (2005b) applied an algorithm to register mapped $\mathrm{T}_{2}$ values to anatomical regions for comparison of differences between groups of 18 months old APP/PS mice, PS mice and non-Tg mice, as well as between groups of 6 weeks old and 18 months old PS and non-Tg mice. Helpern et al. (2004) attributed the $\mathrm{T}_{2}$ reduction to the higher amyloid plaque burden in these areas. However, this was inferred from the similarity of the pattern of hypointensities demonstrated by ex vivo MR imaging in APP/PS1 mice to the distribution of plaques in histology described in the literature.

El Tannir El Tayara et al. (2006) included histological analysis of amyloid and iron along with measured $\mathrm{T}_{1}, \mathrm{~T}_{2}$ and proton density values in a longitudinal study. They found that $\mathrm{T}_{2}$ changes correlated with increasing amyloid load. However, $\mathrm{T}_{2}$ was also correlated with age and the lack of a significant difference between $\mathrm{T}_{2}$ in APP/PS1 mice and PS1 mice in most brain structures suggests other age-related effects that are distinct from amyloid deposition as main factors in $\mathrm{T}_{2}$ decrease. Furthermore, mean Fe did not correlate with $\mathrm{T}_{2}$ or age, so that $\mathrm{Fe}$ may not participate significantly in age-related $\mathrm{T}_{2}$ decrease. In another experiment $\mathrm{T}_{2}$ was measured in young APP/PS1 mice whose brains exhibited amyloidosis in the subiculum but had no detectable iron accumulation on histology (El Tayara Nel et al., 2007). The reduced $\mathrm{T}_{2}$ in this region is seen by the authors to support the role of other mechanisms in this effect, such as the hydrophobicity of dense amyloid aggregates or other tissue alterations. A further longitudinal analysis of quantitative parametric maps of $\mathrm{T}_{2}$ by Falangola et al. (2007), in which mice of various AD genotypes (Tg2576, PS1, and PS/APP) were imaged suggested the reduction in $T_{2}$ involves both $A \beta$-dependent and $A \beta$-independent mechanisms. In addition, it was suggested that iron could be a 


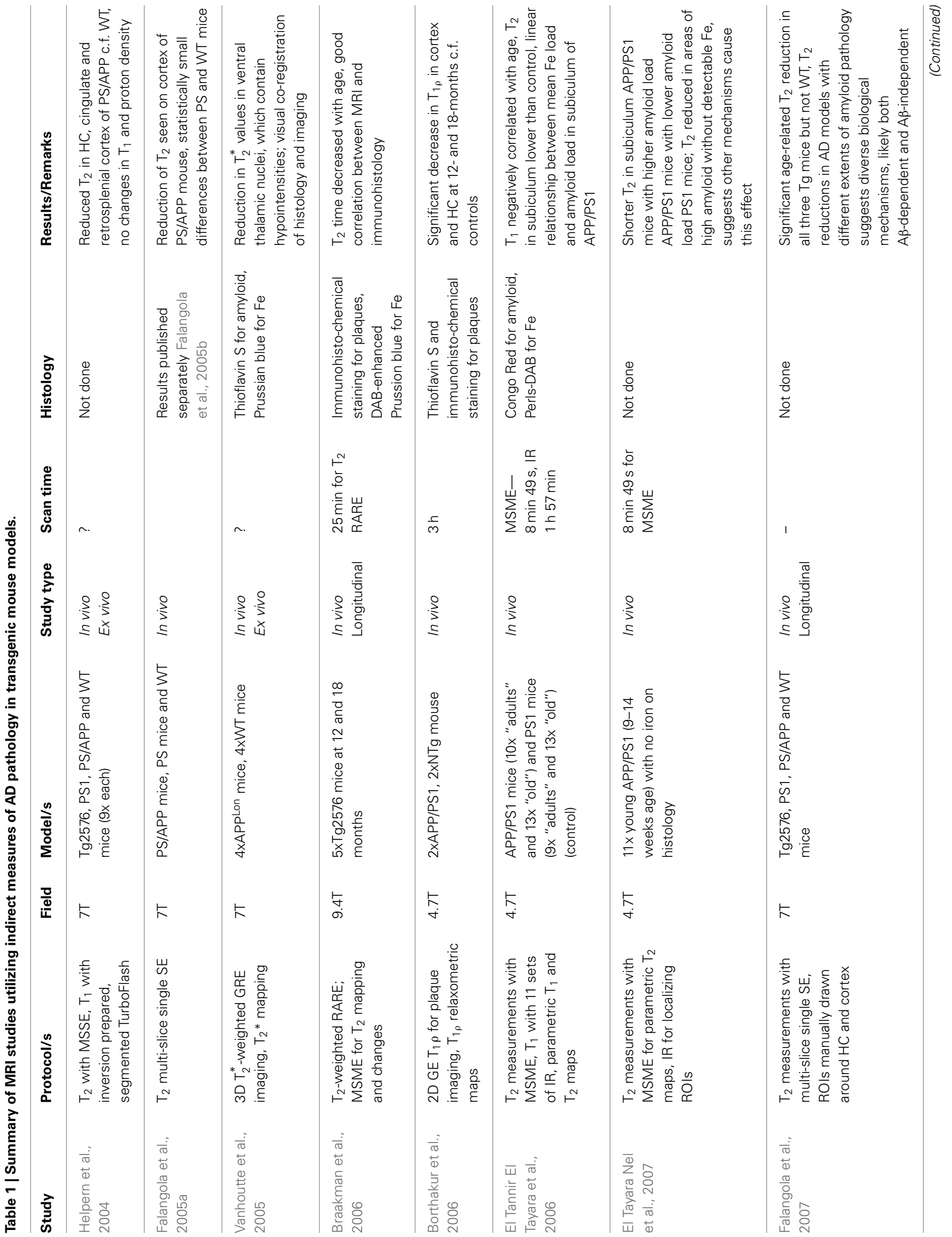




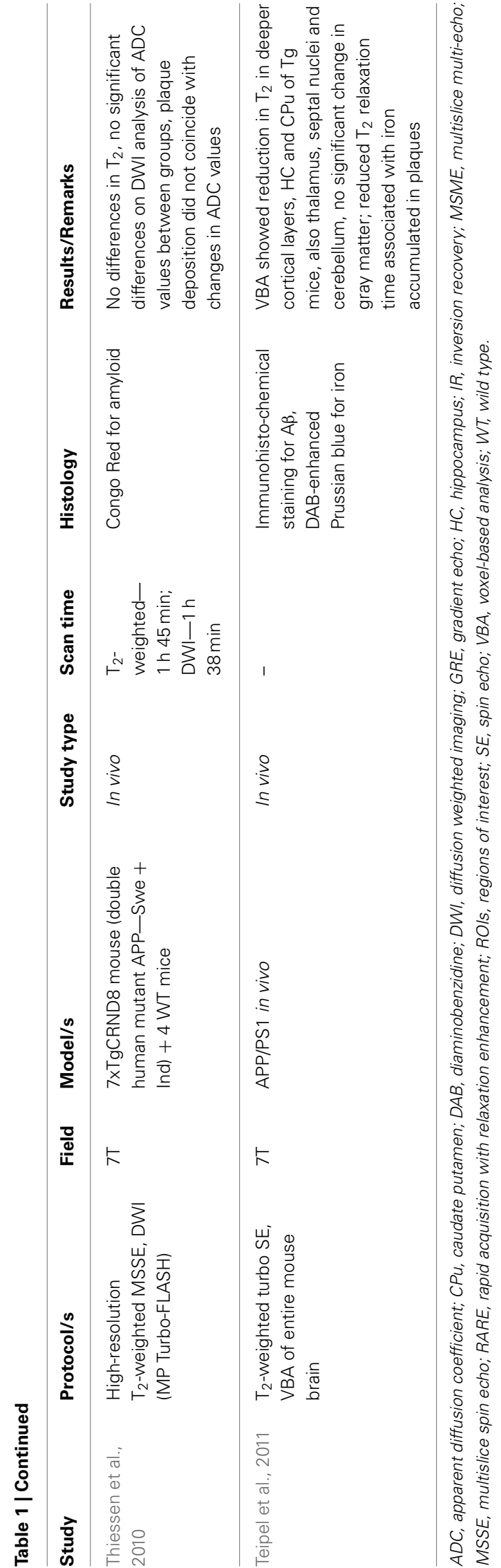

more significant factor for reducing $T_{2}$ in older animals from 12 months.

Both Braakman et al. (2006) and more recently Teipel et al. (2011) in their discussions support a role for plaque-associated $\mathrm{Fe}$ in reducing $\mathrm{T}_{2}$ relaxation times. As with El Tannir El Tayara et al. (2006) they registered $T_{2}$ maps with histological investigations of amyloid and $\mathrm{Fe}$, with Teipel et al. making additional use of automated voxel-based analysis in studying $\mathrm{T}_{2}$ differences. The consistent co-localization of $\mathrm{Fe}$ with plaques supports the association of Fe accumulation in plaques with reduced $\mathrm{T}_{2}$ (Teipel et al., 2011). Vanhoutte et al. (2005) in their study mapped $T_{2}^{*}$ relaxation with $3 \mathrm{D}$ gradient echo (GRE) imaging and found a reduction in $\mathrm{T}_{2}^{*}$ values in the thalamus of singly transgenic mice, where the majority of plaques were associated with $\mathrm{Fe}$.

Taking a different approach Borthakur et al. (2006) analyzed the transverse relaxation in the rotating frame, $T_{1 \rho}$ and found this was significantly reduced in the cortex and hippocampus of APP/PS1 mice compared to non-Tg mice. Delineating plaques on imaging and histology, they attributed the effect to amyloid burden but noted it may also result from decreased blood flow and blood volume. Another approach was taken by Thiessen et al. (2010), who used DWI to map ADC values in the neocortex and hippocampus of mice encoding two human APP mutations and registering these with histology. They found no significant change in $A D C$ values compared to controls, suggesting $A \beta$ deposition does not contribute to any diffusional changes if and when they are seen.

Zhang et al. (2004) were first to report on identification of amyloid plaques on MRI imaging in $\mathrm{AD}$ transgenic mice without exogenous contrast-enhancement (refer to Table 2). Using a three-dimensional $\mathrm{T}_{2}$-weighted multiple spin echo (SE) protocol to image ex vivo brains, they visualized numerous hypointensities, which corresponded to amyloid deposits seen on histology. At the same time another group were also able to demonstrate plaques on ex vivo images using a $\mathrm{T}_{2}$-weighted multi-slice fast $\mathrm{SE}$ sequence (Helpern et al., 2004; Lee et al., 2004). Advancing on these achievements, Jack et al. (2004) established the feasibility of in vivo plaque imaging, acquiring scans of APP/PS1 mice with $\mathrm{T}_{2}$ weighted SE and $\mathrm{T}_{2}^{*}$-weighted GRE. In subsequent longitudinal study they further validated the use of $\mathrm{T}_{2}$-weighted $\mathrm{SE}$ for imaging amyloid plaques in vivo, visualizing plaques in mice at the earliest age of 9 months with a minimum size of $35 \mu \mathrm{m}$ (Jack et al., 2005). In their comparison of $\mathrm{T}_{2}$-weighted $\mathrm{SE}$ to $\mathrm{T}_{2}^{*}$-weighted GRE imaging, they found the disadvantage of longer acquisition time with SE is offset by its superior ability to resolve smaller plaques. Meanwhile the time efficiency of $\mathrm{T}_{2}^{*}$-weighted GRE is countered by susceptibility artifacts and its overestimation of the size of some plaques (Jack et al., 2004). Nonetheless there have since been several more studies investigating amyloid imaging with GRE sequences as well as further applications of SE protocols (Vanhoutte et al., 2005; Borthakur et al., 2006; Braakman et al., 2006; Faber et al., 2007; Chamberlain et al., 2009; Dhenain et al., 2009; Meadowcroft et al., 2009; Wengenack et al., 2011).

One of the main aims of the MR studies is to reduce the scanning time required. Zhang et al. (2004) required $14 \mathrm{~h}$ to acquire their images while Lee et al. (2004) managed to scan ex vivo mouse brains in $2 \mathrm{~h}$, a time more compatible with in vivo mouse imaging. 


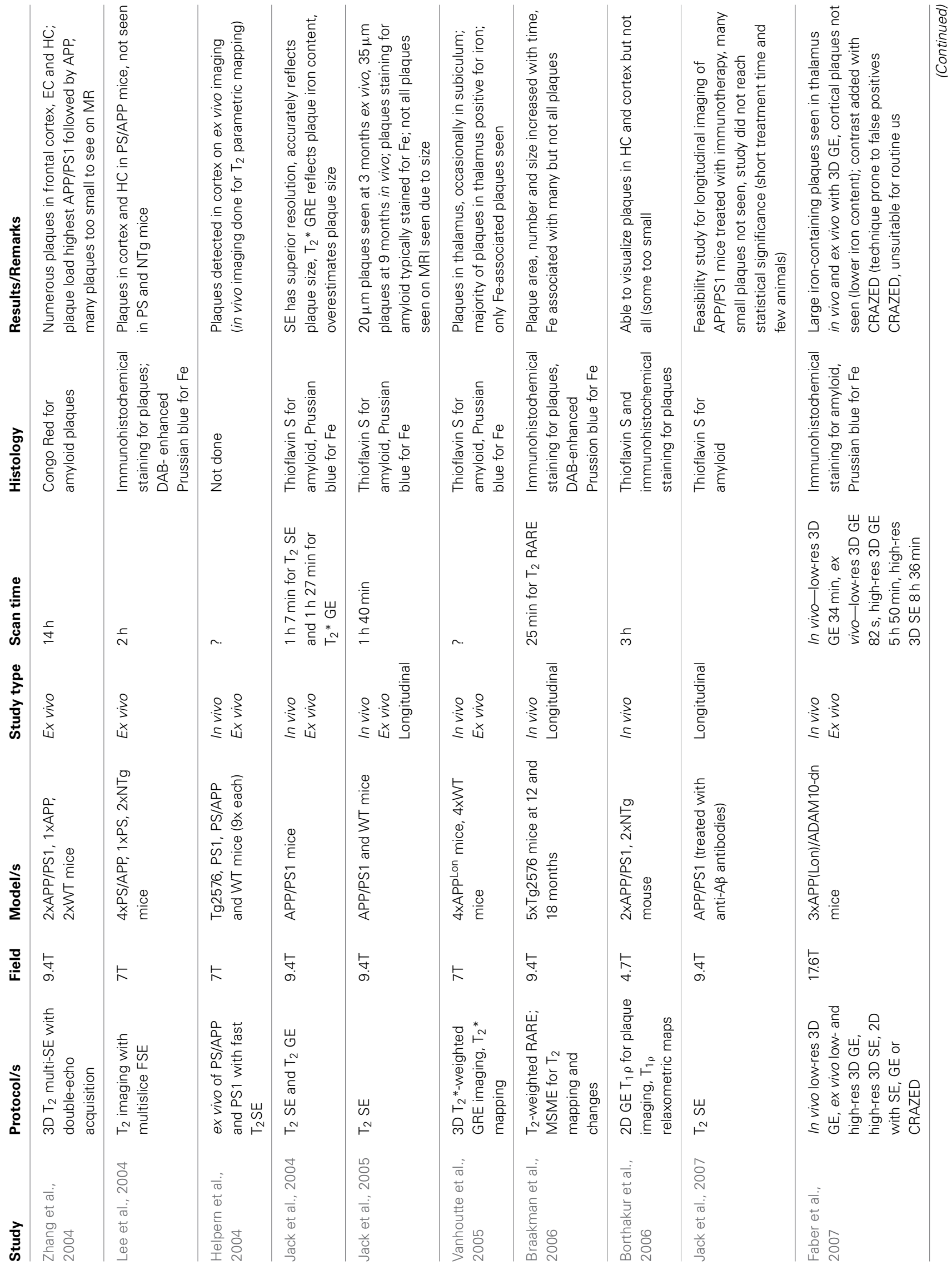



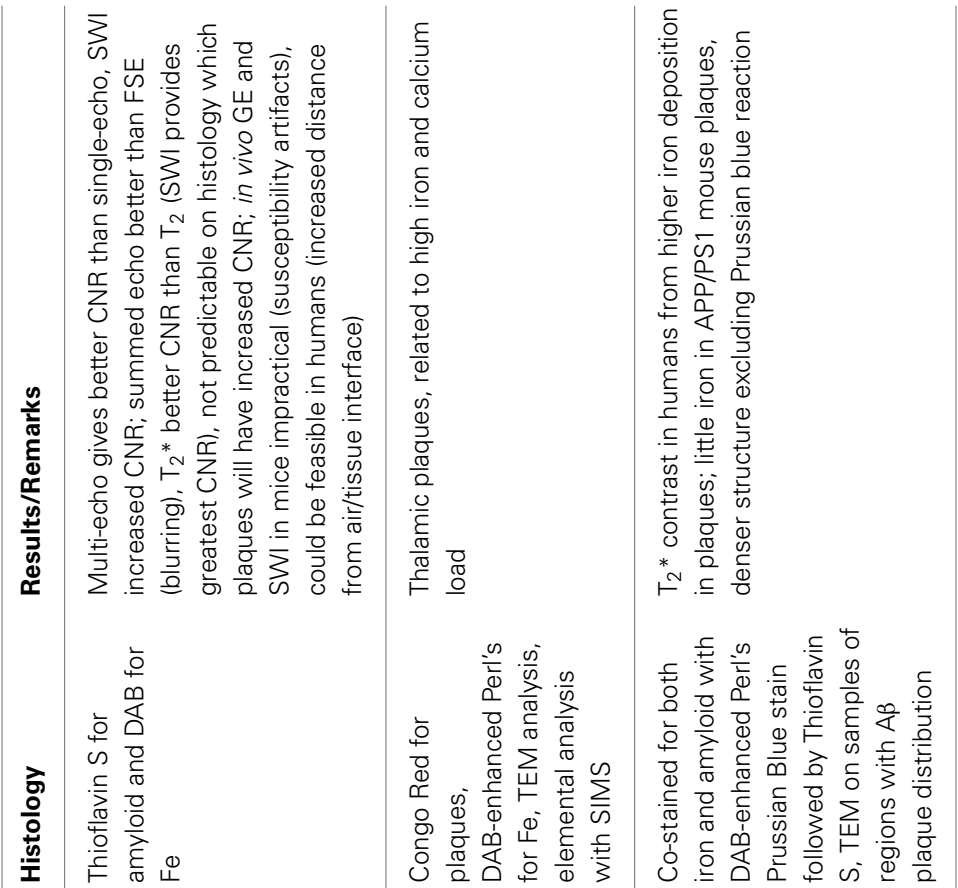

을 응

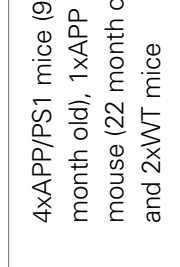

它

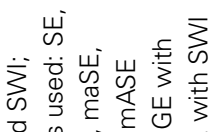

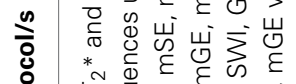

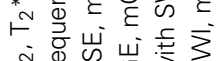

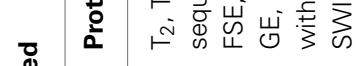

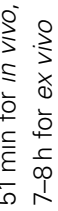

$\stackrel{5}{\varepsilon}$

$\frac{c}{6}$

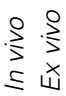

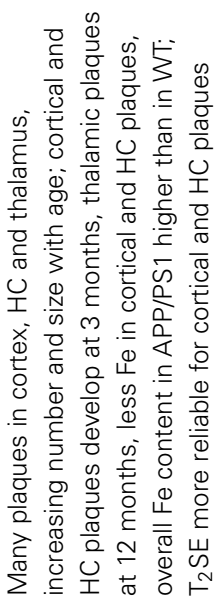

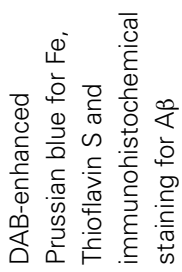

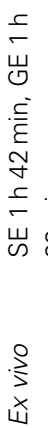

$\frac{.0}{\varepsilon}$

守

o

嵌峲

D

要

永离

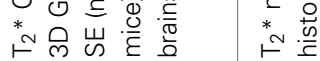

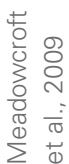

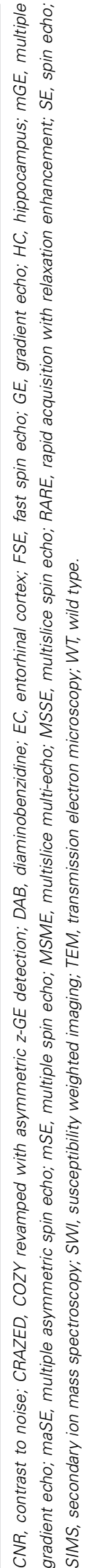


Jack et al. acquired in vivo $\mathrm{T}_{2}$-weighted $\mathrm{SE}$ and $\mathrm{T}_{2}^{*}$-weighted GRE in $1 \mathrm{~h} 7 \mathrm{~min}$ and $1 \mathrm{~h} 27 \mathrm{~min}$ respectively. The time efficiency of GRE sequences has meant in vivo scanning times of less than an hour have been achieved (Faber et al., 2007; Dhenain et al., 2009). Faber and co-workers, for example, were able to achieve significant gains in time efficiency with the use of bright contrast obtained by correlated spectroscopy (COZY) revamped with asymmetric z-GRE detection (CRAZED) sequences. However, in these studies only thalamic plaques could be visualized and few if any cortical plaques were seen (Faber et al., 2007; Dhenain et al., 2009). On the other hand, Braakman et al. (2006) imaged cortical plaques using a $\mathrm{T}_{2}$-weighted rapid acquisition with relaxation enhancement (RARE) sequence that resulted in a scan time of $25 \mathrm{~min}$.

Thalamic plaques are more readily identified on MR imaging (Dhenain et al., 2009). This has been attributed to variations in tissue Fe deposition and Fe density in plaques (Jack et al., 2004; Faber et al., 2007; Dhenain et al., 2009). This leads to the question of the precise mechanisms by which transverse relaxation is changed leading to contrast in plaques relative to surrounding brain tissue on imaging. Comparing DAB-enhanced Perl's staining for Fe with the distribution of amyloid deposits in histology of mice brains shows they are frequently co-localized, indicating Fe association with plaques (Jack et al., 2004; Lee et al., 2004; Vanhoutte et al., 2005; Braakman et al., 2006). Thalamic plaques have high concentrations of Fe associated with them (Faber et al., 2007; Dhenain et al., 2009). Higher Fe concentrations produce a "blooming effect" on $\mathrm{T}_{2}^{*}$-weighted imaging, which can lead to overestimation of plaque size (Jack et al., 2004). However, plaques in the cortex and hippocampus of $\mathrm{AD}$ mice have less associated Fe than thalamic plaques in mice and amyloid plaques in human AD brains (Vanhoutte et al., 2005; Faber et al., 2007; Leskovjan et al., 2009, 2011; Meadowcroft et al., 2009; Wengenack et al., 2011). Illustrating this difference, in the studies using $\mathrm{T}_{2}^{*}$-weighted GRE sequences only thalamic plaques were clearly visualized (Vanhoutte et al., 2005; Faber et al., 2007; Dhenain et al., 2009). The difference in size, morphology, mineral content and amyloid fibrillar structure in these thalamic plaques and their lack of correlation with brain amyloidosis make them of little use in the development of MR imaging (Dhenain et al., 2009; Chamberlain et al., 2011; Wengenack et al., 2011). Nonetheless the influence of Fe susceptibility effects on $\mathrm{T}_{2}$ relaxation is still regarded as a major factor in achieving contrast when visualizing plaques in the cortex and hippocampus of $\mathrm{AD}$ transgenic mice (Helpern et al., 2004; Jack et al., 2004; Lee et al., 2004; Zhang et al., 2004; Braakman et al., 2006; Chamberlain et al., 2009; Meadowcroft et al., 2009; Wengenack et al., 2011).

Conversely, the fact that $\mathrm{Fe}$ is much reduced in amyloid plaques in mice and secondly that not all visualized plaques contain Fe suggest that there may be other sources of MR contrast in amyloid plaques. Accelerated $\mathrm{T}_{2}$ relaxation in plaques may be partially due to exchange between tissue water protons and protons in plaque-associated proteins (Jack et al., 2004) or impaired cell physiology with resultant reduced cerebral blood flow (Helpern et al., 2004; Borthakur et al., 2006). It has also been suggested that reduced T2 signal may be due to exclusion of water molecules from the dense hydrophobic core of amyloid deposits (Lee et al.,
2004; Wengenack et al., 2011), though the fact that the proton density in plaques is only slightly reduced compared to normal cortical tissue does not lend this support to this proposition (Chamberlain et al., 2009; Wengenack et al., 2011). Part of the difficulty in understanding the properties of plaques in MR imaging has been due to the imprecise nature of co-registering the plaques seen on imaging with histological localization of amyloid deposits and Fe. Meadowcroft et al. overcame this difficulty by using a coil optimized for scanning histological sections, allowing very accurate co-registration between images and histology. Thus, they were able to directly compare the difference in Fe content in plaques in APP/PS1 mice with human $\mathrm{AD}$ brain tissue and control mice and analyse its effect on $\mathrm{T}_{2}{ }^{*}$-weighted imaging. Iron was shown to play a role in the contrast in amyloid in human $\mathrm{AD}$ brains on imaging, yet plaques in APP/PS1 mice were as easily observed despite having significantly less Fe. This plaque-associated signal loss may be explained by the interactions of water with the highly compacted amyloid fibril mass (Meadowcroft et al., 2009).

Attempts to enhance the endogenous contrast in plaques with improved scanning efficiency and reliability has resulted in a wide range of image acquisition techniques being investigated. These have involved $\mathrm{T}_{2}$-weighted $\mathrm{SE}$ sequences and $\mathrm{T}_{2}^{*}$-weighted and $\mathrm{T}_{1 \rho}$ GRE sequences, and included methods for contrast enhancement such as susceptibility-weighted imaging (SWI) (refer to Table 2). In a comparison of multiple techniques applied to mouse brain imaging by Chamberlain et al. (2009), $\mathrm{T}_{2}^{*}$ was shown to give superior plaque contrast-to-noise ratio (CNR) compared to $\mathrm{T}_{2}$ while GRE gave consistently higher CNR compared to SE. They further investigated the combination of SWI with multiple asymmetric SE, GRE and multiple GRE to increase plaque contrast. As with CRAZED, SWI relies on Fe for contrast enhancement. They found that SW1 sequences provided the greatest CNR on ex vivo imaging of cortical plaques. However, the use of GRE and SWI in vivo is complicated by susceptibility artifacts caused by the air-to-tissue and/or fat-to-skull interfaces. Jack and co-workers consistently found $\mathrm{T}_{2}$-weighted $\mathrm{SE}$ sequences more reliable in the detection of plaques as they are less reliant on their Fe content (Jack et al., 2004; Chamberlain et al., 2009; Wengenack et al., 2011).

One of the main concerns with direct imaging of amyloid plaques is the lack of specificity in the signal changes that might correspond to $A \beta$ deposits (Poduslo et al., 2002; Jack et al., 2004). $\mathrm{T}_{1}$ and proton density values do not differ significantly between amyloid deposits and normal brain tissue (Helpern et al., 2004; Chamberlain et al., 2009). On the other hand Fe, a major source of accelerated $\mathrm{T}_{2}$ and $\mathrm{T}_{2}^{*}$ decay is non-specific. Consequently blood vessels or microhaemorrhages can be evident in $\mathrm{T}^{*}$ and SW1 images and thus also seen in normal brains (Poduslo et al., 2002; Jack et al., 2004). A strategy aimed at overcoming these initiatives, and analogous to radionuclide imaging, is the use of amyloid-targeting ligands labeled with MR contrast-enhancing molecules.

One molecule shown to bind with high affinity and specificity to amyloid deposits was A $\beta$ itself (Poduslo et al., 2002; Wadghiri et al., 2003; Sigurdsson et al., 2008; Braakman et al., 2009; Yang et al., 2011). Following $A \beta$ labeled radionuclide experiments, 
Poduslo and co-workers surmized that labeling with gadolinium (Gd) could enhance MR image contrast by acceleration of $\mathrm{T}_{1}$ relaxation and to a lesser extent $\mathrm{T}_{2}$ relaxation of nearby water molecules. They were able to demonstrate contrast enhancement of amyloid plaques on both $\mathrm{T}_{1}$-weighted and $\mathrm{T}_{2}$-weighted images of ex vivo mouse brains following injection of synthetic $\mathrm{A} \beta_{40}$ chelated to Gd prior to euthanization of the animal model. Following this study Wadghiri et al. investigated the in vivo application of enhancement with $\mathrm{A} \beta_{40}$ attached to Gd and monocrystalline iron oxide nanoparticles (MION). They were able to detect plaques on in vivo $\mathrm{T}_{2}$-weighted $\mathrm{SE}$ and $\mathrm{T}_{2}^{*}$-weighted GRE images but $\mathrm{T}_{1}$-weighted imaging required prohibitively long scan times. Sigurdsson et al. showed again that Gd is able to enhance contrast on $\mathrm{T}_{2}^{*}$-weighted imaging while Yang et al. investigated the use of ultrasmall superparamagnetic iron oxide (USPIO) nanoparticles coupled to $A \beta_{42}$ with $T_{2}^{*}$-weighted GRE. $T_{1}$-weighted imaging is less sensitive to the magnetic susceptibility effects of Fe and so demonstrated fewer artifacts from Fe-associated structures such as white matter and blood vessels. Consequently there is ongoing research into developing $\mathrm{T}_{1}$-weighted sequences for use with Gd-labeled contrast enhancing agents (Wengenack et al., 2008).

Two disadvantages are evident with the use of intravenously administered $A \beta$ peptides to label plaques. Firstly, the impermeable nature of the normal blood-brain-barrier necessitates co-administration of mannitol or complexion of ligands with polyamines such as putrescine to facilitate passage of the ligand into the brain to reach its target (Wadghiri et al., 2003; Delatour et al., 2006; Braakman et al., 2009). Secondly, A $\beta$ is potentially toxic. Sigurdsson et al. (2008) developed a ligand using the truncated $A \beta_{1-30}$ peptide chelated to $\mathrm{Gd}$. Other groups have developed ligands based upon the amyloidophilic compound Congo Red often used in histological staining (Higuchi et al., 2005; Li et al., 2010). In a particularly novel approach, Higuchi et al. (2005) utilized a Congo Red-based compound labeled with ${ }^{19} \mathrm{~F}$. This compound was able to cross the blood-brain-barrier and bind specifically to amyloid. ${ }^{19} \mathrm{~F}$ is MR-sensitive but present in only very low concentrations in biological tissues, resulting in very little non-specific background signal (Higuchi et al., 2005; Braakman et al., 2009). Another strategy to overcome the toxic effects of $A \beta$ ligands is to use anti-A $\beta$ monoclonal antibodies linked to Gd (Wengenack et al., 2008).

In summarizing, the availability of $\mathrm{Tg}$ mouse models of $\mathrm{AD}$ has greatly accelerated the progress made in MR amyloid imaging by providing a convenient and efficient platform for developing techniques. In particular, the ability to correlate acquired MR images with histology has been invaluable to understanding pathophysiology and its MR behavior. Despite the limitations so far, the advances that have been made show a greater potential that remains achievable as technology and techniques improve.

\section{POSITRON EMISSION TOMOGRAPHY IMAGING}

Following the development of functional FDG PET imaging in patients with $\mathrm{AD}$, the feasibility of detecting and monitoring similar changes in cerebral metabolism in $\mathrm{AD}$ mouse models was investigated (Reiman and Caselli, 1999; Valla et al., 2002,
2006, 2008; Dubois et al., 2010; Nicholson et al., 2010). FDG autoradiography in the brains of a variety of $\mathrm{AD}$ mouse models, ranging from single transgenic to triple transgenic mice, revealed hypometabolism in the posterior cingulate cortex consistent with findings in human studies (Reiman and Caselli, 1999; Valla et al., 2002, 2006, 2008; Nicholson et al., 2010). However, these findings did not translate to any detectable change on in vivo FDG PET in mice (Kuntner et al., 2009).

Furthermore, amyloid imaging in mouse models of AD has not shown the same effective results as has been achieved in humans. This contrasts with MRI studies, where conversely promising findings in animal studies have yet to translate to consistent human application. Initial PET studies using PIB in transgenic $\mathrm{AD}$ mice did not detect any difference in ligand retention between control mice and either Tg2576 or APP/PS1 (Klunk et al., 2005; Toyama et al., 2005). The lack of significant difference has been explained by reduced cerebral perfusion along with a reduction in the density of high affinity ligand binding sites in the plaques in transgenic mice (Klunk et al., 2005; Toyama et al., 2005; Kuntner et al., 2009; Higuchi et al., 2010). The latter may be attributed to the co-deposition of both rodent and human $A \beta$ fibrils in mouse plaques, disrupting the formation of high affinity binding sites (Ye et al., 2006; Higuchi et al., 2010). Similarly, imaging with the probe FDNNP in Tg2576 mice did not differentiate them from control mice (Kuntner et al., 2009), despite its successful application in a triple transgenic rat model of AD (Kepe et al., 2006; Teng et al., 2011).

One way of overcoming the reduced density of high affinity binding sites is by the administration of PIB synthesized with high specific radioactivity, thereby reducing blockage of sites by non-radioactive ligands and improving the plaque specific signal (Maeda et al., 2007; Higuchi, 2009). This method has enabled demonstration of amyloidosis with PIB in the hippocampus and neocortex of transgenic APP23 mice compared to age-matched controls (Maeda et al., 2007, 2011; Higuchi, 2009). In turn, the ability to image amyloid in vivo in transgenic mice enables longitudinal studies for monitoring the effectiveness of anti-amyloid interventions (Maeda et al., 2007, 2011; Higuchi, 2009). Also, combining amyloid imaging with other PET ligands, such as those specific for markers of neuroinflammation, can help further the understanding of the associated molecular and cellular mechanisms of $\mathrm{AD}$ pathology and experimental therapeutic approaches (Maeda et al., 2007, 2011; Higuchi, 2009; Higuchi et al., 2010). Studies exemplifying this have demonstrated a decline in hippocampal amyloid following passive immunization with anti-A $\beta$ antibodies in transgenic mice, while concurrently revealing associated microglial activation and increased neuroinflammation (Maeda et al., 2007, 2011; Higuchi, 2009).

Notwithstanding these important advances, the use of PET in preclinical small animal imaging in $\mathrm{AD}$ remains constrained by technical considerations. The spatial resolution, of current generation scanners, which can range from 0.5 to $3 \mathrm{~mm}$, is insufficient in the context of the small size of mouse brain structures (Nikolaus et al., 2004; Kuntner et al., 2009; Dubois et al., 2010). Difficulties also arise from partial volume error that affects volume definition and radioactivity measurements in small volumes of interest (Nikolaus et al., 2004; Kuntner et al., 2009). 


\section{COMPUTED TOMOGRAPHY IMAGING AND MAGNETIC RESONANCE SPECTROSCOPY}

The superior resolution of MR for visualizing brain tissue has meant CT has been seldom utilized as an option for imaging amyloid pathology in mice. Nonetheless, a few studies have explored CT neuroimaging. Hyde et al. (2009) combined structural information from CT with fluorescence molecular tomography with a fluorescent oxazine dye for in vivo quantification of amyloid plaque burden in APP23 mice. Others have applied CT directly to imaging amyloid plaques, either with phase-contrast X-ray CT (Noda-Saita et al., 2006) or with diffraction-enhanced imaging (DEI) in micro-CT mode (Connor et al., 2009). Both Noda-Saita et al. (2006) and Connor et al. (2009) demonstrated individual plaques on ex vivo imaging with high spatial resolution comparable to histological analysis. However, the high level of irradiation associated with phase-contrast CT and its inability to image the brain within the skull meant it could not be applied in vivo (Noda-Saita et al., 2006). According to Connor et al. DEI could overcome the issue of in vivo imaging by using higher energy $\mathrm{x}$-rays to reduce attenuation from the skull. Nonetheless, these limitations of plaque imaging with CT and the lack of any clear advantage over MR plaque imaging has resulted in no studies being published to date with in vivo $\mathrm{CT}$ imaging in $\mathrm{AD}$ mouse models.

In contrast, MRS has had greater utility in evaluating pathological changes in a number of AD mouse models (Marjanska et al., 2005; von Kienlin et al., 2005; Oberg et al., 2008; Chen et al., 2009; Salek et al., 2010; Xu et al., 2010). Analysis of the metabolic profile of PS2APP (von Kienlin et al., 2005) and APP/PS1 mice (Marjanska et al., 2005; Oberg et al., 2008) by in vivo MRS revealed significant decreases in the NAA and glutamate levels relative to $\mathrm{Cr}$ with advancing age. These changes in transgenic models, in particular the APP/PS1 model are concordant with those seen in human AD brains (Marjanska et al., 2005; Michaelis et al., 2009). Marjanska and co-workers also observed an increase with age in the concentration of myo-inositol (m-Ins), a marker of glial activation, in APP/PS1 mice compared to wild-type controls. This finding was later confirmed by Chen et al. (2009) and has confirmed the significance of m-Ins as an alternative metabolic marker to NAA, enabling investigation of other disease processes in AD (Oberg et al., 2008). Taken together the results from these studies provide good support for the role of MRS in preclinical research in $\mathrm{AD}$.

\section{CURRENT STATUS OF NEUROIMAGING BIOMARKERS IN ALZHEIMER'S DISEASE}

Technological advances in neuroimaging have yielded a burgeoning wealth of information on the pathology of AD. Coupled with our growing understanding of the molecular and cellular basis of the disease, these advances have opened new possibilities and potential for new approaches. Foremost of these advances has been that of PET, which has exemplified the versatility of neuroimaging in both preclinical and clinical research in $\mathrm{AD}$. Early development of ligands specific for neuroreceptors revealing changes in neurotransmitter systems, such as the cholinergic system and dopaminergic system, together with functional imaging enabled by FDG-PET, provided initial insights into the molecular mechanisms of AD (Vallabhajosula, 2011). However, the development of amyloid-binding probes has markedly enhanced the potential for PET imaging in the diagnosis of $\mathrm{AD}$. The initial ligand synthesized for this purpose, FDNNP, which exhibits nonspecific binding to both amyloid and NFT pathology, was quickly surpassed by the amyloid-specific ligand $\left[{ }^{11} \mathrm{C}\right]-\mathrm{PIB}$. Since the introduction of PIB, in vivo amyloid imaging has demonstrated the capacity to diagnose AD with good accuracy and to differentiate $\mathrm{AD}$ from dementia due to a number of other causes. It has also provided immense insights into clinicopathology, revealing key information that has greatly influenced our current understanding of the amyloid hypothesis of $\mathrm{AD}$ pathogenesis. The lack of correlation between amyloid burden and clinical severity in $\mathrm{AD}$, along with the significant proportion of cognitively normal elderly with detectable amyloid, has recently resulted in the presence of cerebral amyloid being viewed in an increasingly complex manner in disease development. That $\mathrm{A} \beta$ pathology plays a key role remains widely accepted, but the pathological mechanisms of $\mathrm{AD}$ may occur prior to the formation of amyloid plaques. Nonetheless, the utility of amyloid imaging is firmly established and is reflected by ongoing development into amyloid-targeting ligands (Vallabhajosula, 2011), particularly ${ }^{18} \mathrm{~F}$-labeled ligands that exhibit more specific binding and have greater clinical availability due to the $2 \mathrm{~h}$ half-life.

The evolution of MRI techniques has also provided important new perspectives for the development of MRI biomarkers in $\mathrm{AD}$. There are now a number of quantitative structural MRI studies demonstrating volume loss in the medial temporal lobe, particularly the hippocampus, as a significant and early marker of disease development in AD (Ewers et al., 2012) [a recent study using MR imaging in infants (2-25 months of age) of different apolipoprotein E status revealed that APOE E4 carriers had decreased gray matter volume in areas typically affected in $\mathrm{AD}$, raising the possibility that a genetic predisposition to $\mathrm{AD}$ is reflected by early anatomical alterations in the brain (Dean et al., 2014)]. The neuronal loss underpinning the macroscopic regional gray matter atrophy seen on $\mathrm{T}_{1}$-weighted $\mathrm{MRI}$ can be further investigated at the microscopic level, by techniques such as MTR and MRS. In a recent study of quantitative parametric mapping of MTR parameters and gray matter volumetric maps in AD patients, Giulietti et al. (2012) suggest that the reduction in MTR may reflect not only amyloid deposition, but also metabolic derangement due to mitochondrial dysfunction, as the affected regions exhibit both PIB accumulation and reduced glucose metabolism on FDG-PET. Hence MTR can give information complementary to conventional structural MRI, which may have further value in investigating other groups such as MCI subjects and other dementia patients. Similarly MRS, by enabling detection of metabolites reflecting neuronal loss and gliosis can provide further information on pathophysiological changes to complement structural imaging changes in MCI and early AD. Using this multimodal approach, Westman et al. (2011) in their multivariate analysis of MRI volumetric measures and MRS measures improved the discrimination between early AD patients and healthy controls. DTI has also been used to reveal damage to white matter tracts in and between known affected areas in $\mathrm{AD}$, such as in the posterior cingulum and between the 
prefrontal cortex and the medial temporal lobe or parietal cortex. Advanced MRI techniques have been applied to reveal important information on the consequences of neuronal dysfunction and neuronal loss. Axonal degeneration and white matter changes that occur secondary to neuronal loss can be investigated with DTI. Yukashev and colleagues demonstrated that both macroscopic changes shown by volumetric analysis and microstructural changes revealed by DTI lead to metabolic changes in the posterior cingulate cortex (Yakushev et al., 2011a,b). Hattori et al. (2012) utilized DTI to analyse the fornix, which contains efferent fibers from the hippocampus, in $\mathrm{AD}$ patients and patients with normal pressure hydrocephalus (NPH) which is another cause of progressive dementia. Their tract-specific analysis revealed differing patterns of damage between NHP and AD patients, suggesting the potential of this approach in differentiating these two causes of dementia. Functional MRI, measuring changes in regional brain activity arising from gray and white matter changes and particularly loss of functional connectivity, is another emerging MRI technique able to complement structural MRI. In their analysis of volumetric gray matter change and resting state fMRI measurements, Dai et al. (2012) were able to discriminate between early $\mathrm{AD}$ patients and healthy controls with an accuracy of $89.5 \%$. However, validation of these MRI techniques, applied individually and in multimodal approaches requires further investigation in larger groups (Drago et al., 2011).

Recent research publications have shown a clear evolution from single-modality imaging to multimodality imaging studies of neuroimaging biomarkers of AD. The complementary information yielded by multiple imaging approaches gives greater insight into the pathophysiological processes occurring in vivo. An improved understanding of the temporal relationship of emerging neuroimaging biomarkers is also important. The dynamic model of imaging biomarkers in $\mathrm{AD}$ (Frisoni et al., 2010; Jack et al., 2010; Cavedo and Frisoni, 2011; Ewers et al., 2012) reflects the developing concept of $\mathrm{AD}$ as a continuum of pathophysiological processes, with clinical AD being a late manifestation (refer to Figure 1). Amyloid imaging not only supports the classification of amnestic MCI as the prodromal stage, but also provides evidence for an asymptomatic preclinical stage in which the pathological processes for $\mathrm{AD}$ have already been triggered (Cavedo and Frisoni, 2011; Ewers et al., 2012). PIB imaging has revealed up to $50 \%$ of MCI patients and up to $30 \%$ of cognitively normal elderly have significant amyloid deposition, associated with changes in brain structure and function (Ewers et al., 2012; Mormino et al., 2012). In MCI, both PIB positivity and the presence and rate of hippocampal atrophy on MRI are predictive of conversion to clinical AD. However, as reflected in the dynamic imaging biomarker model, the amyloid burden has reached a plateau in MCI and hippocampal atrophic changes are already significant following the onset of clinical AD (Cavedo and Frisoni, 2011; Ewers et al., 2012). This suggests that biomarkers have less relevance in the latter stages of the disease continuum. Furthermore, PET imaging and structural MRI do not offer any advantage in accuracy and utility over clinical criteria for $\mathrm{AD}$ diagnosis, hence part of the reason why they are yet to be accepted as part of diagnostic criteria (McKhann et al., 2011).

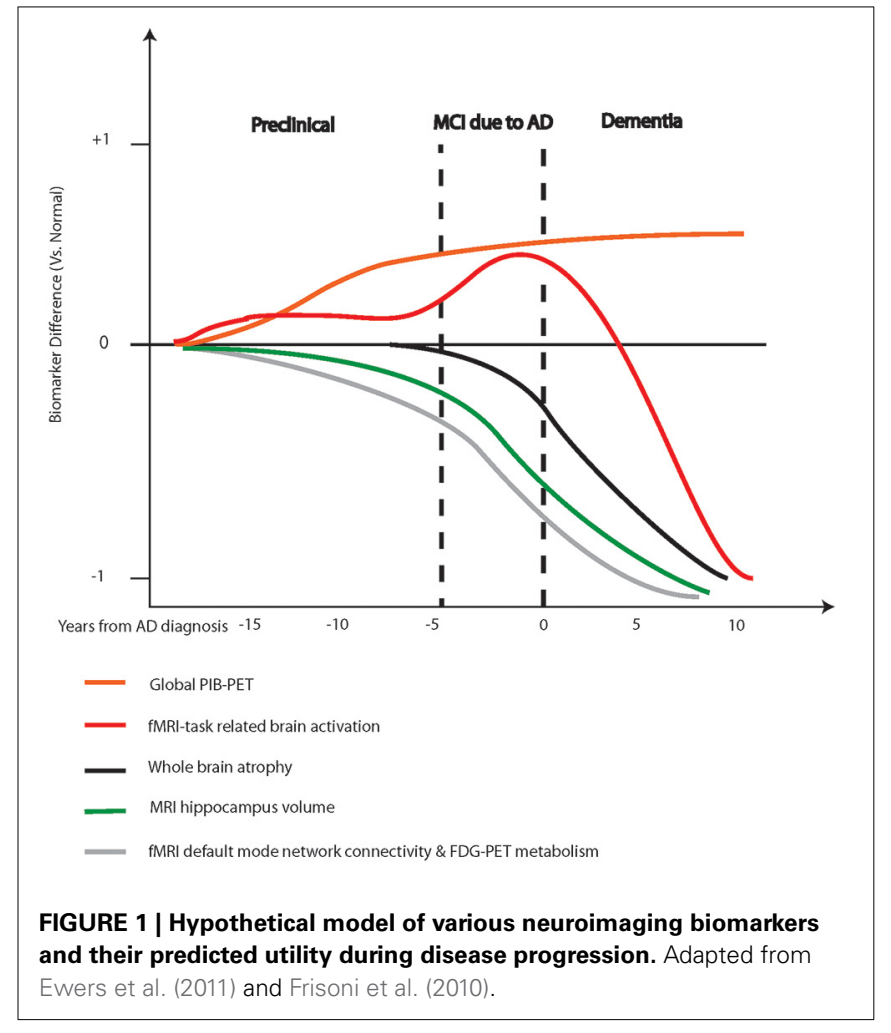

Consequently, the focus of neuroimaging has now shifted to defining the preclinical stage of AD (Sperling et al., 2011). As mentioned, a proportion of cognitively normal individuals are known to harbor significant amyloid as evidenced by PIB retention, with the onset of this deposition occurring after the age of 50 in people without familial AD (Ewers et al., 2012). It is possible that slight elevations in PIB in cognitively normal elderly may have biological relevance (Mormino et al., 2012). When studied with FDG-PET, cognitively normal individuals carrying the ApoE $\varepsilon 4$ demonstrate early abnormalities (Ewers et al., 2012). Similarly, PIB-positive elderly may demonstrate lack of deactivation and disrupted functional connectivity in the DMN with fMRI, and greater atrophy in the hippocampus and cingulate cortex on structural MRI (Ewers et al., 2012). Consequently, defining preclinical $\mathrm{AD}$ has been a major focus, leading to recommendation of a research framework for working toward this goal by the National Institute on Aging-Alzheimer's Association workgroups (Sperling et al., 2011). Neuroimaging is an integral component in developing the preclinical AD definition, as reflected in the recommended draft operational research framework. Further research, particularly longitudinal studies, are needed to contribute toward elucidating the full continuum of AD pathophysiology.

Our understanding of the pathological mechanisms in AD has been advanced by the extensive application of neuroimaging techniques to visualize and understand in vivo neuropathology. The role of synaptic failure in AD has informed studies in $\mathrm{AMRI}$, while neuroinflammation and mitochondrial dysfunction is important in interpretation of MRS and MTR findings. Additionally, the role of metal dyshomeostasis in $\mathrm{AD}$ pathogenesis has suggested 
other approaches to imaging. Variations in Fe distribution in the brain are detectable by MRI (Haacke et al., 2005; Bartzokis et al., 2007), thereby suggesting it can be potentially be applied to study the analysis of Fe dysregulation in $\mathrm{AD}$. Techniques to analyse the distribution of $\mathrm{Fe}$ through variations in magnetic relaxivity ( $\mathrm{R}$ and $\mathrm{R}^{*}$ ) values have been carried out in post-mortem $\mathrm{AD}$ brains (Antharam et al., 2012). Nakada et al. (2008) utilized SWI in MRI on a $7 \mathrm{~T}$ scanner to visualize plaque-like pathology in patients with AD. However, their sample size was small and their study could not be correlated with histology. Studies of other aspects of AD pathology, such as the strengthening evidence for the primary role of $A \beta$ oligomers in neurotoxicity and the importance of NFTs in the pathology cascade, will require novel neuroimaging developments. Further insights into the molecular aspects of $\mathrm{AD}$ may provide opportunities for clinical imaging applications, and enable further progress on defining preclinical AD. Ultimately, neuroimaging based upon $\mathrm{AD}$ patholophysiology may bring about the realization of accurate early diagnosis, thereby providing the opportunity for early preventative interventions, which can be monitored for efficacy by tracking changes in disease processes using neuroimaging techniques.

\section{TRANSLATING NEUROIMAGING: UNDERSTANDING AND INTEGRATING PATHOPHYSIOLOGICAL MECHANISMS IN MOUSE MODELS}

Transgenic AD mouse models are imperfect replicas of the human disease. This has significant implications for the application and interpretation of current neuroimaging findings in animal models. The expression of human $A \beta$ in mice affects the physicochemical properties of the formed plaques, which contain both human and rodent $A \beta$. Apart from altered fibril structure, mouse plaques differ in the concentration of the associated metals, in particular their Fe content. Furthermore, these models fail to reproduce the full spectrum of AD pathology evident in human brains, suggesting that other factors or key pathological mechanisms are missing. For example, single transgenic mice do not exhibit neuronal loss despite $A \beta$ deposition, though this is changed with the introduction of multiple genes (Elder et al., 2010). Also, NFTs are not found in transgenic $\mathrm{AD}$ mice unless a tau mutation is introduced (Elder et al., 2010; Balducci and Forloni, 2011), However, these triple-transgenic mice may not be wholly relevant to $\mathrm{AD}$ as tau mutations are not a feature of $\mathrm{AD}$. It may be that the much shorter lifespan of mice precludes key necessary pathological processes associated with human aging, or alternatively these variations may again be attributed to differences between mouse and human proteins (Elder et al., 2010). Another suggestion is, due to their limited AD phenotype, transgenic mice may instead represent models of preclinical AD (Woodhouse et al., 2009; Zahs and Ashe, 2010). In either case, the transgenic mouse model is non-etheless an invaluable asset in the investigation of the pathophysiological mechanisms of the disease. Mouse studies have helped elucidate the role of $A \beta$ accumulation and other pathological processes, including oxidative stress, inflammation and metal dyshomeostasis in the development of neuropathology (reviewed in Balducci and Forloni, 2011). Bidirectional translation between human research and preclinical studies in mice is also fundamental in developing our understanding of $\mathrm{AD}$ and furthering advances in neuroimaging biomarkers (Higuchi et al., 2010). Furthermore, the time efficiency and cost-effectiveness afforded by the accelerated formation of neuropathology and their short lifespan, makes them particularly useful for longitudinal neuroimaging studies (Strome and Doudet, 2007; Waerzeggers et al., 2010).

The most extensive use of mouse models for neuroimaging in $\mathrm{AD}$ has been in MR imaging studies. The technical difficulties of applying cognitive paradigms to provoke responses in rodents and the need to anaesthetize them for scanning has meant that only a few fMRI studies have been reported (Benveniste et al., 2007), The detection of brain atrophy in transgenic mice has varied between structural MRI studies, and atrophic changes do not appear to correlate with the degree of $A \beta$ deposition (Balducci and Forloni, 2011). Furthermore, the pattern and mechanisms of atrophy in mice appear to differ from those in human AD (Delatour et al., 2006; Maheswaran et al., 2009). These inconsistencies in structural imaging studies may be addressed using newer mouse models, such as the APPxPS1Ki mouse, which exhibits both early onset amyloid- $\beta$ deposition and subsequent neuronal loss (Faure et al., 2011). Other studies, using MRS in transgenic mice to investigate changes in the metabolites NAA, choline and mIns, have closely paralleled findings from human studies (Barba et al., 2008), and have provided important insights into the progression of pathological changes. MRS changes are associated with areas exhibiting amyloid deposition (Salek et al., 2010; Xu et al., 2010), though altered metabolites may be detectable in mice before accumulation of plaques and major histological changes, at an early stage of the disease.

By far the majority of endeavors using MRI in transgenic mice have been for developing imaging of amyloid plaques (see Figure 2B). Various image acquisition protocols have now been investigated to improve the resolution and the plaque-specific contrast and to reduce scanning times. Techniques sensitive to the susceptibility effects of plaques, $\mathrm{T}_{2}$ - and $\mathrm{T}_{2}^{*}$-weighted imaging are able to provide good contrast for plaque imaging, while further enhancement with SWI has the potential to shorten the duration of scanning to clinically acceptable times before MR amyloid imaging is translated from preclinical mouse studies to human clinical research. Despite promising results from numerous studies, a number of issues are still to be resolved. The majority of mouse imaging studies utilize ultra-high field strength magnets of 9.4 Tesla, while most clinical scanner magnets are 1.5 or 3 Tesla. Excluding susceptibility artifacts, arising from other structures giving similar signal on $\mathrm{T}_{2}$ - and $\mathrm{T}_{2}^{*}$-weighted images or from the skull-air interface on SWI, is a significant technical challenge. Also, the relationship between the MRI signal and the intrinsic biochemical properties of amyloid plaques needs further clarification. Mouse plaques contain less Fe than human plaques (Leskovjan et al., 2009; Meadowcroft et al., 2009), which suggests different mechanisms are responsible for the decay of transverse relaxation in mouse plaques compared to human plaques (Meadowcroft et al., 2009). Alternatively, enhancing contrast with plaque-specific contrast agents could circumvent the reliance on the intrinsic susceptibility signal of plaques using MRI. As with PET ligand development, mouse models lend themselves 


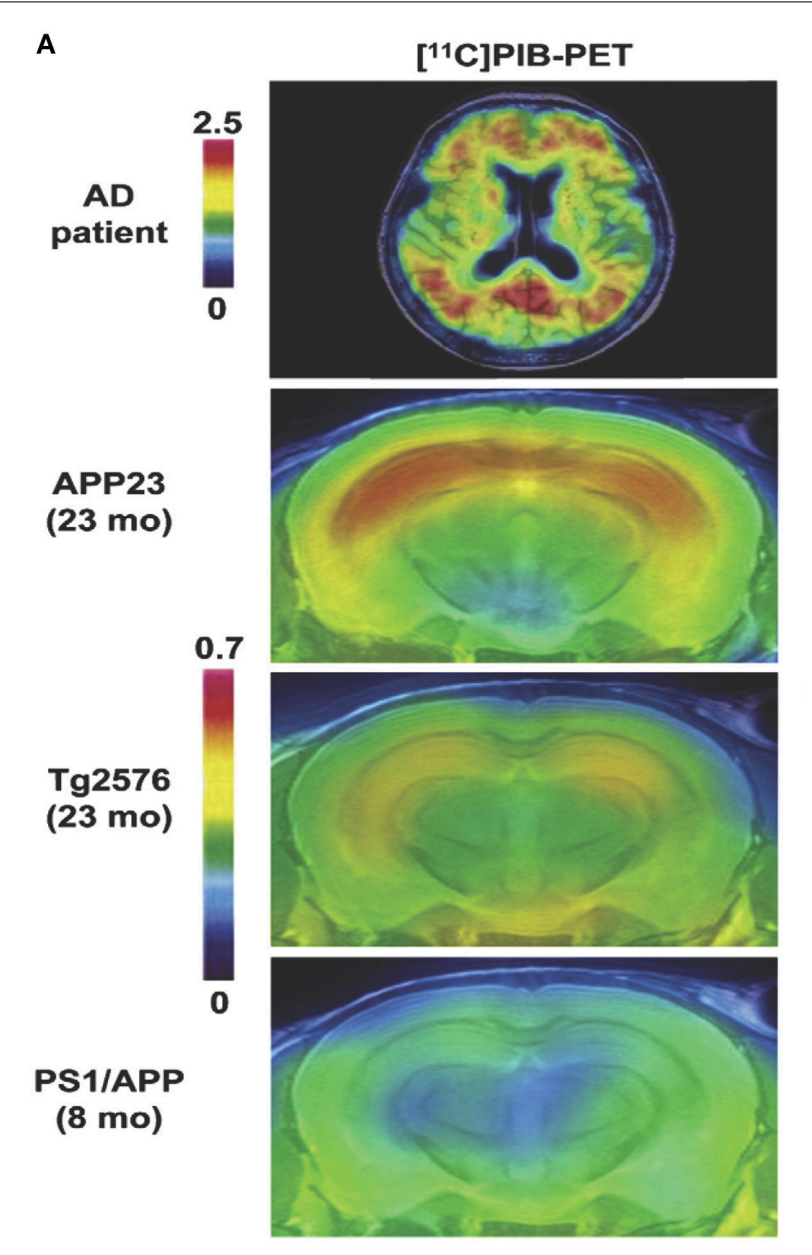

FIGURE 2 | (A) [11C]-PIB-PET images illustrating amyloid depositions in brains of an AD patient (axial view) and different strains of APP transgenic or PS-1/APP double transgenic mice (coronal view) merged onto anatomical MRI maps. Human and mouse images are differently scaled according to the maximal binding potential for the radiotracer in each species, as indicated by vertical bars from Higuchi et al. (2010). (B) Five-way anatomic spatial coregistration of a 24-month-old APP/PS1 AD transgenic mouse brain. Ex vivo MRI scans of matched sections imaged using either a (A) $T_{2} S E$ or (D) $T_{2}^{*}$
B

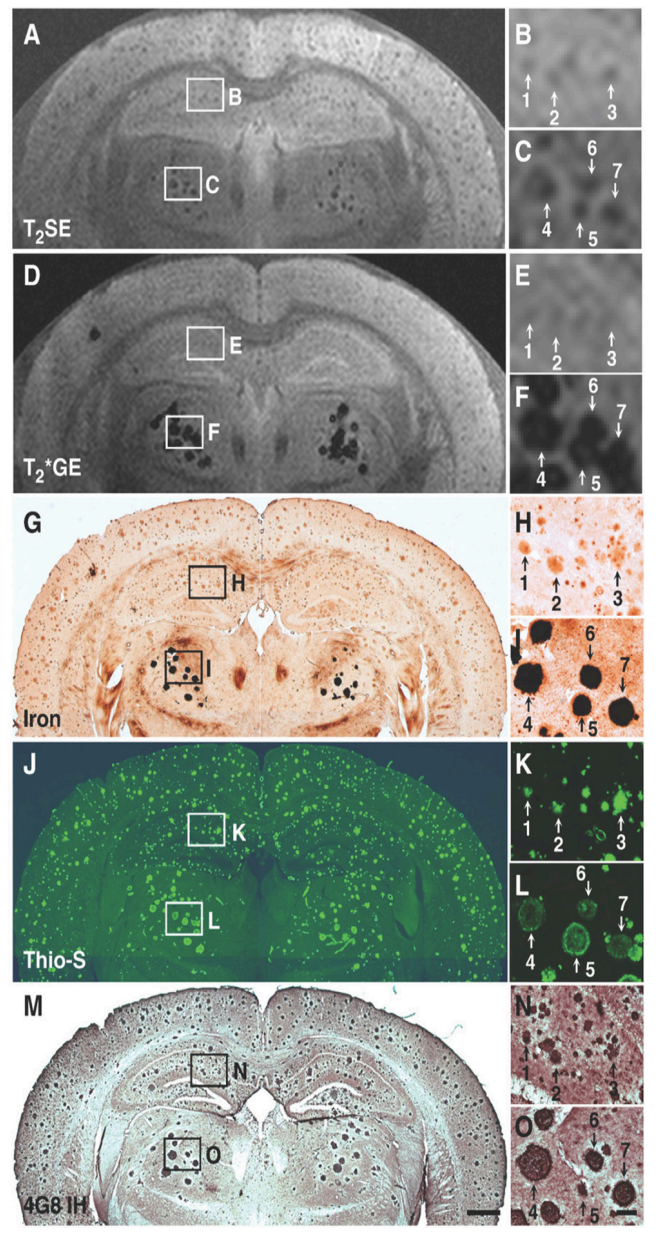

GE pulse sequence. Matched adjacent histological sections processed with (G) DAB-enhanced iron staining, $(\mathrm{J})$ thioflavine S amyloid staining, or

(M) anti-A $\beta$ peptide immunohistochemistry. Scale bar $=500 \mu m$. $(B, E, H, K, N)$ Higher magnification of hippocampal plaques positively matched by spatial coregistration. Corresponding plaques are labeled with numbers when present in a particular section. (C,F,I,L,O) Higher magnification of thalamic plaques positively matched by spatial coregistration. (O) Scale bar $=100 \mu \mathrm{m}$ from Wengenack et al. (2011). readily to the development and testing of plaque specific contrast agents.

In contrast to MRI imaging, the PET amyloid imaging has been less effectively translated to transgenic mouse models (see Figure 2A). As previously mentioned, a major reason for this is the paucity in high affinity ligand binding sites in mouse amyloid, which can partly be overcome by synthesizing ligands with higher specific radioactivity (Waerzeggers et al., 2010). Improving the spatial resolution of preclinical PET scanners is another challenge. Most studies of new PET ligands targeting amyloid have relied on ex vivo autoradiography to localize ligand binding in the brains of transgenic mice (Ono et al., 2011; Vallabhajosula, 2011). Yousefi et al. (2011), in their evaluation of [ $\left.{ }^{11} \mathrm{C}\right]$-Labeled Imidazo[2,1b]benzothiazoles as PET tracers, demonstrate that improvements in small animal PET scanners have enabled in vivo imaging in mouse models to contribute toward ligand development.
Furthermore, in vivo PET in mice provides immense potential for furthering the understanding of pathological mechanisms and development of ligands specific for AD neuroimaging (Higuchi et al., 2010; Klohs and Rudin, 2011). Multi-tracer studies have been particularly valuable in elucidating pathological relationships in mice, such as the loss of noradrenergic neurons and inflammatory reactions with decreased metabolism (Waerzeggers et al., 2010). Maeda et al. (2007) demonstrated not only the feasibility of PET amyloid imaging of transgenic mice using PIB with high specific radioactivity, but also combined PIB with PET markers for glial activation application in longitudinal monitoring of immunotherapy in mice. Their subsequent study investigating glial responses in mouse models of $\mathrm{AD}$ and tau pathologies with PET offered important insights into the pathological mechanisms at work (Maeda et al., 2011). In particular, their findings suggest a link between upregulation of microglial inflammatory 
responses by $\mathrm{A} \beta$ deposits and conversion of glial responses to a neurotoxic form mediating tau pathology and neuronal loss (Higuchi et al., 2010; Maeda et al., 2011). This may explain the absence of neuronal loss seen in $\mathrm{AD}$ mouse models that lack tau pathology (Higuchi et al., 2010). The stimulation of specific immune responses by $\mathrm{A} \beta$ and its adverse effect on tau pathology and neuronal survival has implications for immunotherapy in the treatment of AD (Higuchi et al., 2010; Maeda et al., 2011). These findings highlight the value of PET imaging in the evaluating therapeutic interventions, by enabling key pathophysiological mechanisms to be monitored.

As neuroimaging in $\mathrm{AD}$ mouse models advances in parallel to clinical research, new imaging approaches will be informed by developments in our understanding of $\mathrm{AD}$ pathophysiology. Structural MRI has gained new perspectives from incorporating DTI and MTI, by elucidating early microstructural changes that can be correlated with the development of atrophic changes. Analysis methods such as voxel-based morphometry and deformation-based morphometry are being used to study subtle atrophy in vulnerable brain regions in $\mathrm{AD}$ transgenic mice. MR amyloid imaging can be expected to further advance, with ongoing developments in amyloid specific MR contrast agents. For example, a novel recent approach taken by Higuchi et al. (2005) and further developed by Yanagisawa et al. (2011) involved labeling amyloid with ${ }^{19} \mathrm{~F}$-containing compounds. As biological tissues contain no ${ }^{19} \mathrm{~F}$, detection of plaques can be improved by reduction in the background non-specific signal (Higuchi et al., 2005; Yanagisawa et al., 2011). Similarly novel approaches for PET ligand development have been explored. An example of this is the targeting of metal-associated $A \beta$ aggregates with the metal chelator, clioquinol labeled with an iodine radioisotope (Roney et al., 2009; Kulkarni et al., 2010). In a parallel approach, Fodero-Tavoletti et al. (2010) used bis(thosemicarbazonato) $\mathrm{Cu}^{\mathrm{II}}$ complexes, which have been shown to facilitate intracellular $\mathrm{Cu}$ delivery, coupled with positron emitting ${ }^{64} \mathrm{Cu}$ as a PET tracer. As this approach does not rely on uptake of $\mathrm{Cu}$ by plaques and consequently does not correlate with amyloid burden, they suggest it may offer complementary information to other methods.

\section{CONCLUSION}

Our understanding of the pathophysiological mechanisms of AD has been significantly enhanced through the application of neuroimaging to visualize these processes in vivo. At the same time, our knowledge of AD pathophysiology is helping to inform new directions for imaging approaches for studying neuropathology. With the focus shifted to earlier diagnosis at a prodromal or even asymptomatic stage of $\mathrm{AD}$, current imaging methods are important to define these stages. Early diagnostic criteria will depend not only on current biomarkers combined in a multimodal approach, but also the development of novel techniques for neuroimaging that may offer more specific biomarkers of disease, intimately reflecting the underlying pathophysiology. This is also important to the efficacy and success of developing new interventions for altering the course of the disease. Ultimately, without effective interventions, the ability to diagnose $\mathrm{AD}$ at any stage will allow us to be little more than informed observers to an unfolding health crisis.

\section{ACKNOWLEDGMENTS}

Paul A. Adlard is supported by an Australian Research Council (ARC) Future Fellowship, Gary F. Egan is supported by a National Health and Medical Research Council Principal Researcher Fellowship, Ashley I. Bush is supported by a National Health and Medical Research Council Australia Fellowship. In addition, the Florey Institute of Neuroscience and Mental Health acknowledge the strong support from the Victorian Government and in particular the funding from the Operational Infrastructure Support Grant.

\section{REFERENCES}

Agostinho, P., Cunha, R. A., and Oliveira, C. (2010). Neuroinflammation, oxidative stress and the pathogenesis of Alzheimer's disease. Curr. Pharm. Des. 16, 2766-2778. doi: 10.2174/138161210793176572

Alzheimers, A. (2011). Alzheimer's association report 2011 Alzheimer's disease facts and figures. Alzheimers Dement. 7, 208-244. doi: 10.1016/j.jalz.2011.02.004

Amariglio, R. E., Becker, J. A., Carmasin, J., Wadsworth, L. P., Lorius, N., Sullivan, C., et al. (2012). Subjective cognitive complaints and amyloid burden in cognitively normal older individuals. Neuropsychologia 50, 2880-2886. doi: 10.1016/j.neuropsychologia.2012.08.011

Antharam, V., Collingwood, J. F., Bullivant, J. P., Davidson, M. R., Chandra, S., Mikhaylova, A., et al. (2012). High field magnetic resonance microscopy of the human hippocampus in Alzheimer's disease: quantitative imaging and correlation with iron. Neuroimage 59, 1249-1260. doi: 10.1016/j.neuroimage.2011.08.019

Arendt, T. (2009). Synaptic degeneration in Alzheimer's disease. Acta Neuropathol. 118, 167-179. doi: 10.1007/s00401-009-0536-x

Ashford, J. W., Salehi, A., Furst, A., Bayley, P., Frisoni, G. B., Jack, C. R. Jr., et al. (2011). Imaging the Alzheimer brain. J. Alzheimer's Dis. 26(Suppl. 3), 1-27. doi: 10.3233/JAD-2011-0073

Badea, A., Johnson, G. A., and Jankowsky, J. L. (2010). Remote sites of structural atrophy predict later amyloid formation in a mouse model of Alzheimer's disease. Neuroimage 50, 416-427. doi: 10.1016/j.neuroimage.2009.12.070

Balducci, C., and Forloni, G. (2011). APP transgenic mice: their use and limitations. Neuromolecular Med. 13, 117-137. doi: 10.1007/s12017-010-8141-7

Ballard, C., Gauthier, S., Corbett, A., Brayne, C., Aarsland, D., and Jones, E. (2011). Alzheimer's disease. Lancet 377, 1019-1031. doi: 10.1016/S01406736(10)61349-9

Barba, I., Fernandez-Montesinos, R., Garcia-Dorado, D., and Pozo, D. (2008). Alzheimer's disease beyond the genomic era: nuclear magnetic resonance (NMR) spectroscopy-based metabolomics. J. Cell. Mol. Med. 12, 1477-1485. doi: 10.1111/j.1582-4934.2008.00385.x

Bartzokis, G., Tishler, T. A., Lu, P. H., Villablanca, P., Altshuler, L. L., Carter, M., et al. (2007). Brain ferritin iron may influence age- and genderrelated risks of neurodegeneration. Neurobiol. Aging. 28, 414-423. doi: 10.1016/j.neurobiolaging.2006.02.005

Bartzokis, G., Tishler, T. A., Shin, I. S., Lu, P. H., and Cummings, J. L. (2004). “Brain ferritin iron as a risk factor for age at onset in neurodegenerative diseases," in Redox-Active Metals in Neurological Disorders. Annals of the New York Academy of Sciences, Vol. 1012, eds S. M. Levine, J. R. Connor, and H. M. Schipper (New York, NY: The New York Academy of Sciences), 224-236.

Beckmann, N. (2011). Probing cerebrovascular alterations in alzheimer's disease using mri: from transgenic models to patients. Curr. Med. Imaging Rev. 7, 51-61. doi: 10.2174/157340511794653531

Benveniste, H., Einstein, G., Kim, K. R., Hulette, C., and Johnson, A. (1999). Detection of neuritic plaques in Alzheimer's disease by magnetic resonance microscopy. Proc. Natl. Acad. Sci. U.S.A. 96, 14079-14084. doi: 10.1073/pnas.96.24.14079

Benveniste, H., Ma, Y., Dhawan, J., Gifford, A., Smith, S. D., Feinstein, I., et al. (2007). "Anatomical and functional phenotyping of mice models of Alzheimer's disease by MR microscopy," in Imaging and the Aging Brain. Annals of the New York Academy of Sciences, eds M. J. DeLeon, D. A. Snider, and H. Federoff (New York, NY: The New York Academy of Sciences), 12-29.

Bharadwaj, P. R., Dubey, A. K., Masters, C. L., Martins, R. N., and Macreadie, I. G. (2009). A beta aggregation and possible implications in Alzheimer's 
disease pathogenesis. J. Cell. Mol. Med. 13, 412-421. doi: 10.1111/j.1582 4934.2009.00609.x

Bianchetti, A., and Trabucch, M. (2001). Clinical aspects of Alzheimer's disease. Aging (Milano). 13, 221-230.

Blurton-Jones, M., and Laferla, F. M. (2006). Pathways by which Abeta facilitates tau pathology. Curr. Alzheimer Res. 3, 437-448. doi: $10.2174 / 156720506779025242$

Bokde, A. L., Ewers, M., and Hampel, H. (2009). Assessing neuronal networks: understanding Alzheimer's disease. Prog. Neurobiol. 89, 125-133. doi 10.1016/j.pneurobio.2009.06.004

Borthakur, A., Gur, T., Wheaton, A. J., Corbo, M., Trojanowski, J. Q., Lee, V. M., et al. (2006). In vivo measurement of plaque burden in a mouse model of Alzheimer's disease. J. Magn. Reson. Imaging 24, 1011-1017. doi: 10.1002/jmri.20751

Braakman, N., Matysik, J., van Duinen, S. G., Verbeek, F., Schliebs, R., de Groot, H. J., et al. (2006). Longitudinal assessment of Alzheimer's beta-amyloid plaque development in transgenic mice monitored by in vivo magnetic resonance microimaging. J. Magn. Reson. Imaging 24, 530-536. doi: 10.1002/jmri. 20675

Braakman, N., van Buchem, M. A., Schliebs, R., de Groot, H. J. M., and Alia, A. (2009). Recent advances in visualizing Alzheimer's plaques by magnetic resonance imaging. Curr. Med. Imaging Rev. 5, 2-9. doi: 10.2174/157340509787354741

Brickman, A. M., Small, S. A., and Fleisher, A. (2009). Pinpointing synaptic loss caused by Alzheimer's disease with fMRI. Behav. Neurol. 21, 93-100. doi: $10.1155 / 2009 / 246892$

Brookmeyer, R., Evans, D. A., Hebert, L., Langa, K. M., Heeringa, S. G., Plassman, B. L., et al. (2011). National estimates of the prevalence of Alzheimer's disease in the United States. Alzheimers Dement. 7, 61-73. doi: 10.1016/j.jalz.2010.11.007

Bush, A. I. (2008). Drug development based on the metals hypothesis of Alzheimer's disease. J. Alzheimers Dis. 15, 223-240.

Casadesus, G., Smith, M. A., Zhu, X., Aliev, G., Cash, A. D., Honda, K., et al. (2004). Alzheimer disease: evidence for a central pathogenic role of iron-mediated reactive oxygen species. J. Alzheimer's Dis. 6, 165-169.

Cavedo, E., and Frisoni, G. B. (2011). The dynamic marker hypothesis of Alzheimer's disease and its implications for clinical imaging. Q. J. Nucl. Med. Mol. Imaging 55, 237-249.

Chamberlain, R., Reyes, D., Curran, G. L., Marjanska, M., Wengenack, T. M., Poduslo, J. F., et al. (2009). Comparison of amyloid plaque contrast generated by T-2-weighted, T-2(star)-weighted, and susceptibility-weighted imaging methods in transgenic mouse models of alzheimer's disease. Magn. Reson. Med. 61, 1158-1164. doi: 10.1002/mrm.21951

Chamberlain, R., Wengenack, T. M., Poduslo, J. F., Garwood, M., and Jack, C. R. (2011). Magnetic resonance imaging of amyloid plaques in transgenic mouse models of Alzheimer's disease. Curr. Med. Imaging Rev. 7, 3-7. doi: 10.2174/157340511794653522

Chen, S. Q., Wang, P. J., Ten, G. J., Zhan, W., Li, M. H., and Zang, F. C. (2009). Role of myo-inositol by magnetic resonance spectroscopy in early diagnosis of Alzheimer's disease in APP/PS1 transgenic mice. Dement. Geriatr. Cogn. Disord. 28, 558-566. doi: 10.1159/000261646

Chetelat, G., Villemagne, V. L., Pike, K. E., Baron, J. C., Bourgeat, P., Jones, G., et al (2010). Larger temporal volume in elderly with high versus low beta-amyloid deposition. Brain 133, 3349-3358. doi: 10.1093/brain/awq187

Coimbra, A., Williams, D. S., and Hostetler, E. D. (2006). The role of MRI and PET/SPECT in Alzheimer's disease. Curr. Top. Med. Chem. 6, 629-647. doi: 10.2174/156802606776743075

Connor, D. M., Benveniste, H., Dilmanian, F. A., Kritzer, M. F., Miller, L. M., and Zhong, Z. (2009). Computed tomography of amyloid plaques in a mouse model of Alzheimer's disease using diffraction enhanced imaging. Neuroimage 46, 908-914. doi: 10.1016/j.neuroimage.2009.03.019

Crews, L., Rockenstein, E., and Masliah, E. (2010). APP transgenic modeling of Alzheimer's disease: mechanisms of neurodegeneration and aberrant neurogenesis. Brain Struct. Funct. 214, 111-126. doi: 10.1007/s00429-009-0232-6

Dai, Z., Yan, C., Wang, Z., Wang, J., Xia, M., Li, K., et al. (2012). Discriminative analysis of early Alzheimer's disease using multi-modal imaging and multilevel characterization with multi-classifier (M3). Neuroimage 59, 2187-2195. doi: 10.1016/j.neuroimage.2011.10.003

Dean, D. C. 3rd, Jerskey, B. A., Chen, K., Protas, H., Thiyyagura, P., Roontiva, A., et al. (2014). Brain differences in infants at differential genetic risk for late-onset
Alzheimer disease: a cross-sectional imaging study. JAMA Neurol. 71, 11-22. doi: 10.1001/jamaneurol.2013.4544

Delatour, B., Guegan, M., Volk, A., and Dhenain, M. (2006). In vivo MRI and histological evaluation of brain atrophy in APP/PS1 transgenic mice. Neurobiol. Aging. 27, 835-847. doi: 10.1016/j.neurobiolaging.2005.04.011

Dhenain, M., El Tayara, N. E., Wu, T. D., Guegan, M., Volk, A., Quintana, C., et al. (2009). Characterization of in vivo MRI detectable thalamic amyloid plaques from APP/PS1 mice. Neurobiol. Aging 30, 41-53. doi: 10.1016/j.neurobiolaging.2007.05.018

Dhenain, M., Privat, N., Duyckaerts, C., and Jacobs, R. E. (2002). Senile plaques do not induce susceptibility effects in T-2*-weighted MR microscopic images. NMR Biomed. 15, 197-203. doi: 10.1002/nbm.760

Dickerson, B. C., and Sperling, R. A. (2009). Large-scale functional brain network abnormalities in Alzheimer's disease: insights from functional neuroimaging. Behav. Neurol. 21, 63-75. doi: 10.1155/2009/610392

Drago, V., Babiloni, C., Bartres-Faz, D., Caroli, A., Bosch, B., Hensch, T., et al. (2011). Disease tracking markers for Alzheimer's disease at the prodromal (MCI) stage. J. Alzheimer's Dis. 26(Suppl. 3), 159-199. doi: 10.3233/JAD-20110043

Dubois, A., Herard, A. S., Delatour, B., Hantraye, P., Bonvento, G., Dhenain, M., et al. (2010). Detection by voxel-wise statistical analysis of significant changes in regional cerebral glucose uptake in an APP/PS1 transgenic mouse model of Alzheimer's disease. Neuroimage 51, 586-598. doi: 10.1016/j.neuroimage.2010.02.074

Elder, G. A., Gama Sosa, M. A., and De Gasperi, R. (2010). Transgenic mouse models of Alzheimer's disease. Mt. Sinai J. Med. 77, 69-81. doi: 10.1002/msj. 20159

Ellis, K. A., Szoeke, C., Bush, A. I., Darby, D., Graham, P. L., Lautenschlager, N. T., et al. (2014). Rates of diagnostic transition and cognitive change at 18-month follow-up among 1,112 participants in the Australian imaging, biomarkers and lifestyle flagship study of ageing (AIBL). Int. Psychogeriatr. 26, 543-554. doi: 10.1017/S1041610213001956

El Tannir El Tayara, N., Delatour, B., Le Cudennec, C., Guegan, M., Volk, A., and Dhenain, M. (2006). Age-related evolution of amyloid burden, iron load, and MR relaxation times in a transgenic mouse model of Alzheimer's disease. Neurobiol. Dis. 22, 199-208. doi: 10.1016/j.nbd.2005.10.013

El Tayara Nel, T., Volk, A., Dhenain, M., and Delatour, B. (2007). Transverse relaxation time reflects brain amyloidosis in young APP/PS1 transgenic mice. Magn Reson. Med. 58, 179-184. doi: 10.1002/mrm.21266

Ewers, M., Sperling, R. A., Klunk, W. E., Weiner, M. W., and Hampel, H. (2011) Neuroimaging markers for the prediction and early diagnosis of Alzheimer's disease dementia. Trends Neurosci. 34, 430-442. doi: 10.1016/j.tins.2011. 05.005

Ewers, M., Walsh, C., Trojanowski, J. Q., Shaw, L. M., Petersen, R. C., Jack, C. R. Jr., et al. (2012). Prediction of conversion from mild cognitive impairment to Alzheimer's disease dementia based upon biomarkers and neuropsychological test performance. Neurobiol. Aging. 33, 1203-1214. doi: 10.1016/j.neurobiolaging.2010.10.019

Faber, C., Zahneisen, B., Tippmann, F., Schroeder, A., and Fahrenholz, F. (2007) Gradient-echo and CRAZED imaging for minute detection of Alzheimer plaques in an APPV717I x ADAM10-dn mouse model. Magn. Reson. Med. 57, 696-703. doi: 10.1002/mrm.21201

Falangola, M. F., Ardekani, B. A., Lee, S. P., Babb, J. S., Bogart, A., Dyakin, V. V., et al. (2005b). Application of a non-linear image registration algorithm to quantitative analysis of $\mathrm{T} 2$ relaxation time in transgenic mouse models of $\mathrm{AD}$ pathology. J. Neurosci. Methods. 144, 91-97. doi: 10.1016/j.jneumeth.2004.10.012

Falangola, M. F., Dyakin, V. V., Lee, S. P., Bogart, A., Babb, J. S., Duff, K., et al. (2007). Quantitative MRI reveals aging-associated T-2 changes in mouse models of Alzheimer's disease. NMR Biomed. 20, 343-351. doi: 10.1002/nbm.1163

Falangola, M. F., Lee, S. P., Nixon, R. A., Duff, K., and Helpern, J. A. (2005a). Histological co-localization of iron in A beta plaques of PS/APP transgenic mice. Neurochem. Res. 30, 201-205. doi: 10.1007/s11064-004-2442-x

Faure, A., Verret, L., Bozon, B., El Tannir El Tayara, N., Ly, M., Kober, F., et al. (2011). Impaired neurogenesis, neuronal loss, and brain functional deficits in the APPxPS1-Ki mouse model of Alzheimer's disease. Neurobiol. Aging. 32, 407-418. doi: 10.1016/j.neurobiolaging.2009.03.009

Ferreira, L. K., and Busatto, G. F. (2011). Neuroimaging in Alzheimer's disease: current role in clinical practice and potential future applications. Clinics 66(Suppl. 1), 19-24. doi: 10.1590/S1807-59322011001300003 
Ferri, C. P., Prince, M., Brayne, C., Brodaty, H., Fratiglioni, L., Ganguli, M., et al. (2005). Global prevalence of dementia: a delphi consensus study. Lancet 366, 2112-2117. doi: 10.1016/S0140-6736(05)67889-0

Fiala, J. (2007). Mechanisms of amyloid plaque pathogenesis. Acta Neuropathol. 114, 551-571. doi: 10.1007/s00401-007-0284-8

Fodero-Tavoletti, M. T., Cappai, R., McLean, C. A., Pike, K. E., Adlard, P. A., Cowie, T., et al. (2009). Amyloid imaging in Alzheimer's disease and other dementias. Brain Imaging Behav. 3, 246-261. doi: 10.1007/s11682-009-9067-2

Fodero-Tavoletti, M. T., Villemagne, V. L., Paterson, B. M., White, A. R., Li, Q. X., Camakaris, J., et al. (2010). Bis(thiosemicarbazonato) Cu-64 complexes for positron emission tomography imaging of Alzheimer's disease. J. Alzheimer's Dis. 20, 49-55. doi: 10.3233/JAD-2010-1359

Frisoni, G. B., Fox, N. C., Jack, C. R. Jr., Scheltens, P., and Thompson, P. M. (2010). The clinical use of structural MRI in Alzheimer disease. Nat. Rev. Neurol. 6, 67-77. doi: 10.1038/nrneurol.2009.215

Giulietti, G., Bozzali, M., Figura, V., Spano, B., Perri, R., Marra, C., et al. (2012). Quantitative magnetization transfer provides information complementary to grey matter atrophy in Alzheimer's disease brains. Neuroimage 59, 1114-1122. doi: 10.1016/j.neuroimage.2011.09.043

Glass, C. K., Saijo, K., Winner, B., Marchetto, M. C., and Gage, F. H. (2010). Mechanisms underlying inflammation in neurodegeneration. Cell 140, 918-934. doi: 10.1016/j.cell.2010.02.016

Glodzik-Sobanska, L., Rusinek, H., Mosconi, L., Li, Y., Zhan, J., de Santi, S., et al. (2005). The role of quantitative structural imaging in the early diagnosis of Alzheimer's disease. Neuroimaging Clin. N. Am. 15, 803-826. doi: 10.1016/j.nic.2005.09.004

Golde, T. E., Dickson, D., and Hutton, M. (2006). Filling the Gaps in the abeta; cascade hypothesis of Alzheimer's disease. Curr. Alzheimer Res. 3, 421-430. doi: $10.2174 / 156720506779025189$

Götz, J., and Götz, N. N. (2009). Animal models for Alzheimer's disease and frontotemporal dementia: a perspective. ASN Neuro. 1, 251-264. doi: 10.1042/AN20090042

Götz, J., Schild, A., Hoerndli, F., and Pennanen, L. (2004). Amyloid-induced neurofibrillary tangle formation in Alzheimer's disease: insight from transgenic mouse and tissue-culture models. Int. J. Dev. Neurosci. 22, 453-465. doi: 10.1016/j.ijdevneu.2004.07.013

Haacke, E. M., Chengb, N. Y. C., House, M. J., Liu, Q., Neelavalli, J., Ogg, R. J., et al. (2005). Imaging iron stores in the brain using magnetic resonance imaging. Magn. Reson. Imaging 23, 1-25. doi: 10.1016/j.mri.2004.10.001

Hattori, T., Sato, R., Aoki, S., Yuasa, T., and Mizusawa, H. (2012). Different patterns of fornix damage in idiopathic normal pressure hydrocephalus and Alzheimer disease. AJNR Am. J. Neuroradiol. 33, 274-279. doi: 10.3174/ajnr.A2780

Hedden, T., Van Dijk, K. R., Becker, J. A., Mehta, A., Sperling, R. A., Johnson, K. A., et al. (2009). Disruption of functional connectivity in clinically normal older adults harboring amyloid burden. J. Neurosci. 29, 12686-12694. doi: 10.1523/JNEUROSCI.3189-09.2009

Helpern, J. A., Lee, S. P., Falangola, M. F., Dyakin, V. V., Bogart, A., Ardekani, B., et al. (2004). MRI assessment of neuropathology in a transgenic mouse model of Alzheimer's disease. Magn. Reson. Med. 51, 794-798. doi: 10.1002/mrm. 20038

Herholz, K., and Ebmeier, K. (2011). Clinical amyloid imaging in Alzheimer's disease. Lancet Neurol. 10, 667-670. doi: 10.1016/S1474-4422(11)70123-5

Higuchi, M. (2009). Visualization of brain amyloid and microglial activation in mouse models of Alzheimer's disease. Curr. Alzheimer Res. 6, 137-143. doi: 10.2174/156720509787602906

Higuchi, M., Iwata, N., Matsuba, Y., Sato, K., Sasamoto, K., and Saido, T. C. (2005). $19 \mathrm{~F}$ and $1 \mathrm{H}$ MRI detection of amyloid beta plaques in vivo. Nat. Neurosci. 8, 527-533. doi: 10.1038/nn 1422

Higuchi, M., Maeda, J., Ji, B., Maruyama, M., Okauchi, T., Tokunaga, M., et al. (2010). In vivo visualization of key molecular processes involved in Alzheimer's disease pathogenesis: insights from neuroimaging research in humans and rodent models. Biochim. Biophys. Acta 1802, 373-388. doi: 10.1016/j.bbadis.2010.01.003

Honig, L. S., and Mayeux, R. (2001). Natural history of Alzheimer's disease. Aging (Milano). 13, 171-182.

House, M. J., St Pierre, T. G., Kowdley, K. V., Montine, T., Connor, J., Beard, J., et al. (2007). Correlation of proton transverse relaxation rates (R2) with iron concentrations in postmortem brain tissue from Alzheimer's disease patients. Magn. Reson. Med. 57, 172-180. doi: 10.1002/mrm.21118
House, M. J., St Pierre, T. G., and McLean, C. (2008). 1.4T study of proton magnetic relaxation rates, iron concentrations, and plaque burden in Alzheimer's disease and control postmortem brain tissue. Magn. Reson. Med. 60, 41-52. doi: 10.1002/mrm. 21586

Hyde, D., de Kleine, R., MacLaurin, S. A., Miller, E., Brooks, D. H., Krucker, T., et al. (2009). Hybrid FMT-CT imaging of amyloid-beta plaques in a murine Alzheimer's disease model. Neuroimage 44, 1304-1311. doi: 10.1016/j.neuroimage.2008.10.038

Jack, C. R. Jr., Garwood, M., Wengenack, T. M., Borowski, B., Curran, G. L., Lin, J., et al. (2004). In vivo visualization of Alzheimer's amyloid plaques by magnetic resonance imaging in transgenic mice without a contrast agent. Magn. Reson. Med. 52, 1263-1271. doi: 10.1002/mrm.20266

Jack, C. R. Jr., Knopman, D. S., Jagust, W. J., Shaw, L. M., Aisen, P. S., Weiner, M. W., et al. (2010). Hypothetical model of dynamic biomarkers of the Alzheimer's pathological cascade. Lancet Neurol. 9, 119-128. doi: 10.1016/S1474-4422(09)70299-6

Jack, C. R. Jr., Lowe, V. J., Senjem, M. L., Weigand, S. D., Kemp, B. J., Shiung, M. M., et al. (2008). 11C PiB and structural MRI provide complementary information in imaging of Alzheimer's disease and amnestic mild cognitive impairment. Brain 131(Pt 3), 665-680. doi: 10.1093/brain/awm336

Jack, C. R. Jr., Marjanska, M., Wengenack, T. M., Reyes, D. A., Curran, G. L., Lin, J., et al. (2007). Magnetic resonance imaging of Alzheimer's pathology in the brains of living transgenic mice: a new tool in Alzheimer's disease research. Neuroscientist 13, 38-48. doi: 10.1177/1073858406295610

Jack, C. R. Jr., Wengenack, T. M., Reyes, D. A., Garwood, M., Curran, G. L., Borowski, B. J., et al. (2005). In vivo magnetic resonance microimaging of individual amyloid plaques in Alzheimer's transgenic mice. J. Neurosci. 25, 10041-10048. doi: 10.1523/JNEUROSCI.2588-05.2005

Kawahara, M. (2010). Neurotoxicity of beta-amyloid protein: oligomerization, channel formation and calcium dyshomeostasis. Curr. Pharm. Des. 16, 2779-2789. doi: 10.2174/138161210793176545

Kepe, V., Huang, S. C., Small, G. W., Satyamurthy, N., and Barrio, J. R. (2006). "Visualizing pathology deposits in the living brain of patients with Alzheimer's disease," in Amyloid, Prions, and Other Protein Aggregates, Pt B. Methods in Enzymology, eds I. Kheterpal and R. Wetzel. (San Diego, CA: Elsevier Academic Press Inc), 144-160.

Klohs, J., and Rudin, M. (2011). Unveiling molecular events in the brain by noninvasive imaging. Neuroscientist 17, 539-559. doi: 10.1177/10738584103 83433

Klunk, W. E., Lopresti, B. J., Ikonomovic, M. D., Lefterov, I. M., Koldamova, R. P., Abrahamson, E. E., et al. (2005). Binding of the positron emission tomography tracer Pittsburgh compound-B reflects the amount of amyloid-beta in Alzheimer's disease brain but not in transgenic mouse brain. J. Neurosci. 25, 10598-10606. doi: 10.1523/JNEUROSCI.2990-05.2005

Kulkarni, P. V., Roney, C. A., Antich, P. P., Bonte, F. J., Raghu, A. V., and Aminabhavi, T. M. (2010). Quinoline-n-butylcyanoacrylate-based nanoparticles for brain targeting for the diagnosis of Alzheimer's disease. Wiley Interdiscip. Rev. Nanomed. Nanobiotechnol. 2, 35-47. doi: 10.1002/wnan.59

Kuntner, C., Kesner, A. L., Bauer, M., Kremslehner, R., Wanek, T., Mandler, M., et al. (2009). Limitations of small animal PET imaging with [18F]FDDNP and FDG for quantitative studies in a transgenic mouse model of Alzheimer's disease. Mol. Imaging Biol. 11, 236-240. doi: 10.1007/s11307-009-0198-z

Lee, B. C. P., Mintun, M., Buckner, R. L., and Morris, J. C. (2003). Imaging of Alzheimer's disease. J. Neuroimaging 13, 199-214. doi: 10.1111/j.15526569.2003.tb00179.x

Lee, C. Y. D., and Landreth, G. E. (2010). The role of microglia in amyloid clearance from the AD brain. J. Neural Transm. 117, 949-960. doi: 10.1007/s00702-0100433-4

Lee, S. P., Falangola, M. F., Nixon, R. A., Duff, K., and Helpern, J. A. (2004). Visualization of beta-amyloid plaques in a transgenic mouse model of Alzheimer's disease using MR microscopy without contrast reagents. Magn. Reson. Med. 52, 538-544. doi: 10.1002/mrm.20196

Lehericy, S., Marjanska, M., Mesrob, L., Sarazin, M., and Kinkingnehun, S. (2007). Magnetic resonance imaging of Alzheimer's disease. Eur. Radiol. 17, 347-362. doi: 10.1007/s00330-006-0341-z

Leskovjan, A. C., Kretlow, A., Lanzirotti, A., Barrea, R., Vogt, S., and Miller, L. M. (2011). Increased brain iron coincides with early plaque formation in a mouse model of Alzheimer's disease. Neuroimage 55, 32-38. doi: 10.1016/j.neuroimage.2010.11.073 
Leskovjan, A. C., Lanzirotti, A., and Miller, L. M. (2009). Amyloid plaques in PSAPP mice bind less metal than plaques in human Alzheimer's disease. Neuroimage 47, 1215-1220. doi: 10.1016/j.neuroimage.2009.05.063

Li, S. P., He, H. J., Cui, W. G., Gu, B., Li, J., Qi, Z. X., et al. (2010). Detection of a beta plaques by a novel specific MRI probe precursor CR-BSA-(Gd-DTPA)n in APP/PS1 transgenic mice. Anat. Rec. 293, 2136-2143. doi: 10.1002/ar.21209

Maeda, J., Ji, B., Irie, T., Tomiyama, T., Maruyama, M., Okauchi, T., et al. (2007). Longitudinal, quantitative assessment of amyloid, neuroinflammation, and anti-amyloid treatment in a living mouse model of Alzheimer's disease enabled by positron emission tomography. J. Neurosci. 27, 10957-10968. doi: 10.1523/JNEUROSCI.0673-07.2007

Maeda, J., Zhang, M. R., Okauchi, T., Ji, B., Ono, M., Hattori, S., et al. (2011). In vivo positron emission tomographic imaging of glial responses to amyloid-beta and tau pathologies in mouse models of Alzheimer's disease and related disorders. J. Neurosci. 31, 4720-4730. doi: 10.1523/JNEUROSCI.3076-10.2011

Maheswaran, S., Barjat, H., Bate, S. T., Aljabar, P., Hill, D. L. G., Tilling, L., et al. (2009). Analysis of serial magnetic resonance images of mouse brains using image registration. Neuroimage 44, 692-700. doi: 10.1016/j.neuroimage.2008.10.016

Marjanska, M., Curran, G. L., Wengenack, T. M., Henry, P. G., Bliss, R. L., Poduslo, J. F., et al. (2005). Monitoring disease progression in transgenic mouse models of Alzheimer's disease with proton magnetic resonance spectroscopy. Proc. Natl. Acad. Sci. U.S.A. 102, 11906-11910. doi: 10.1073/pnas.0505513102

Masters, C. L., Cappai, R., Barnham, K. J., and Villemagne, V. L. (2006). Molecular mechanisms for Alzheimer's disease: implications for neuroimaging and therapeutics. J. Neurochem. 97, 1700-1725. doi: 10.1111/j.1471-4159.2006.03989.x

Maynard, C. J., Bush, A. I., Masters, C. L., Cappai, R., and Li, Q. X. (2005). Metals and amyloid-beta in Alzheimer's disease. Int. J. Exp. Pathol. 86, 147-159. doi: 10.1111/j.0959-9673.2005.00434.x

McKhann, G. M., Knopman, D. S., Chertkow, H., Hyman, B. T., Jack, C. R. Jr., Kawas, C. H., et al. (2011). The diagnosis of dementia due to Alzheimer's disease: recommendations from the national institute on Aging-Alzheimer's association workgroups on diagnostic guidelines for Alzheimer's disease. Alzheimer's Dement. 7, 263-269. doi: 10.1016/j.jalz.2011.03.005

Meadowcroft, M. D., Connor, J. R., Smith, M. B., and Yang, Q. X. (2009). MRI and histological analysis of beta-amyloid plaques in both human Alzheimer's disease and APP/PS1 transgenic mice. J. Magn. Reson. Imaging 29, 997-1007. doi: 10.1002/jmri.21731

Mi, K., and Johnson, G. V. (2006). The role of tau phosphorylation in the pathogenesis of Alzheimer's disease. Curr. Alzheimer Res. 3, 449-463. doi: $10.2174 / 156720506779025279$

Michaelis, T., Abaei, A., Boretius, S., Tammer, R., Frahm, J., Schlumbohm, C., et al. (2009). Intrauterine hyperexposure to dexamethasone of the common marmoset monkey revealed normal cerebral metabolite concentrations in adulthood as assessed by quantitative proton magnetic resonance spectroscopy in vivo. J. Med. Primatol. 38, 213-218. doi: 10.1111/j.1600-0684.2009.00342.x

Minati, L., Edginton, T., Bruzzone, M. G., and Giaccone, G. (2009). Current concepts in Alzheimer's disease: a multidisciplinary review. Am. J. Alzheimers Dis. Other Demen. 24, 95-121. doi: 10.1177/1533317508328602

Mistur, R., Mosconi, L., De Santi, S., Guzman, M., Li, Y., Tsui, W., et al. (2009). Current challenges for the early detection of Alzheimer's disease: brain imaging and CSF studies. J. Clin. Neurol. 5, 153-166. doi: 10.3988/jcn.2009.5.4.153

Mormino, E. C., Brandel, M. G., Madison, C. M., Rabinovici, G. D., Marks, S., Baker, S. L., et al. (2012). Not quite PIB-positive, not quite PIB-negative: slight PIB elevations in elderly normal control subjects are biologically relevant. Neuroimage 59, 1152-1160. doi: 10.1016/j.neuroimage.2011.07.098

Morris, J. C. (2003). Dementia update 2003. Alzheimer Dis. Assoc. Disord. 17, 245-258. doi: 10.1097/00002093-200310000-00010

Mosconi, L., Berti, V., Glodzik, L., Pupi, A., De Santi, S., and de Leon, M. J. (2010). pre-clinical detection of Alzheimer's disease using FDG-PET, with or without amyloid imaging. J. Alzheimers Dis. 20, 843-854. doi: 10.3233/JAD-2010-091504

Muller, W. E., Eckert, A., Kurz, C., Eckert, G. P., and Leuner, K. (2010). Mitochondrial dysfunction: common final pathway in brain aging and Alzheimer's disease-therapeutic aspects. Mol. Neurobiol. 41, 159-171. doi: 10.1007/s12035-010-8141-5

Murphy, M. P., and LeVine, H. 3rd. (2010). Alzheimer's disease and the amyloidbeta peptide. J. Alzheimer's Dis. 19, 311-323. doi: 10.3233/JAD-2010-1221

Muskulus, M., Scheenstra, A. E. H., Braakman, N., Dijkstra, J., Verduyn-Lunel, S., Alia, A., et al. (2009). Prospects for early detection of Alzheimer's disease from serial MR images in transgenic mouse models. Curr. Alzheimer Res. 6, 503-518. doi: 10.2174/156720509790147089

Nabuurs, R. J. A., Hegeman, I., Natte, R., van Duinen, S. G., van Buchem, M. A., van der Weerd, L., et al. (2011). High-field MRI of single histological slices using an inductively coupled, self-resonant microcoil: application to ex vivo samples of patients with Alzheimer's disease. NMR Biomed. 24, 351-357. doi: 10.1002/nbm. 1598

Nakada, T., Matsuzawa, H., Igarashi, H., Fujii, Y., and Kwee, I. L. (2008). In vivo visualization of senile-plaque-like pathology in Alzheimer's disease patients by MR microscopy on a 7T system. J. Neuroimaging 18, 125-129. doi: 10.1111/j.1552-6569.2007.00179.x

Nicholson, R. M., Kusne, Y., Nowak, L. A., LaFerla, F. M., Reiman, E. M., and Valla, J. (2010). Regional cerebral glucose uptake in the 3xTG model of Alzheimer's disease highlights common regional vulnerability across $\mathrm{AD}$ mouse models. Brain Res. 1347, 179-185. doi: 10.1016/j.brainres.2010.05.084

Nikolaus, S., Beu, M., Wirrwar, A., Vosberg, H., Muller, H. W., and Larisch, R. (2004). The contribution of small animal positron emission tomography to the neurosciences-a critical evaluation. Rev. Neurosci. 15, 131-156. doi: 10.1515/REVNEURO.2004.15.2.131

Noda-Saita, K., Yoneyama, A., Shitaka, Y., Hirai, Y., Terai, K., Wu, J., et al. (2006). Quantitative analysis of amyloid plaques in a mouse model of Alzheimer's disease by phase-contrast X-ray computed tomography. Neuroscience 138, 1205-1213. doi: 10.1016/j.neuroscience.2005.12.036

Oberg, J., Spenger, C., Wang, F. H., Andersson, A., Westman, E., Skoglund, P., et al. (2008). Age related changes in brain metabolites observed by $1 \mathrm{H}$ MRS in APP/PS1 mice. Neurobiol. Aging 29, 1423-1433. doi: 10.1016/j.neurobiolaging.2007.03.002

Ono, M., Cheng, Y., Kimura, H., Cui, M., Kagawa, S., Nishii, R., et al. (2011). Novel $18 \mathrm{~F}$-labeled benzofuran derivatives with improved properties for positron emission tomography (PET) imaging of beta-amyloid plaques in Alzheimer's brains. J. Med. Chem. 54, 2971-2979. doi: 10.1021/jm200057u

Palop, J. J., and Mucke, L. (2010). Amyloid-beta-induced neuronal dysfunction in Alzheimer's disease: from synapses toward neural networks. Nat. Neurosci. 13, 812-818. doi: $10.1038 / \mathrm{nn} .2583$

Perl, D. P. (2010). Neuropathology of Alzheimer's disease. Mt. Sinai J. Med. 77, 32-42. doi: 10.1002/msj.20157

Philipson, O., Lord, A., Gumucio, A., O’Callaghan, P., Lannfelt, L., and Nilsson, L. N. G. (2010). Animal models of amyloid-beta-related pathologies in Alzheimer's disease. FEBS J. 277, 1389-1409. doi: 10.1111/j.1742-4658.2010.07564.x

Poduslo, J. F., Wengenack, T. M., Curran, G. L., Wisniewski, T., Sigurdsson, E. M., Macura, S. I., et al. (2002). Molecular targeting of Alzheimer's amyloid plaques for contrast-enhanced magnetic resonance imaging. Neurobiol. Dis. 11, 315-329. doi: 10.1006/nbdi.2002.0550

Rabinovici, G. D., and Jagust, W. J. (2009). Amyloid imaging in aging and dementia: testing the amyloid hypothesis in vivo. Behav. Neurol. 21, 117-128. doi: $10.1155 / 2009 / 609839$

Ramani, A., Jensen, J. H., and Helpern, J. A. (2006). Quantitative MR imaging in Alzheimer disease. Radiology 241, 26-44. doi: 10.1148/radiol.2411050628

Reddy, P. H. (2009). Amyloid beta, mitochondrial structural and functional dynamics in Alzheimer's disease. Exp. Neurol. 218, 286-292. doi: 10.1016/j.expneurol.2009.03.042

Reiman, E. M., and Caselli, R. J. (1999). Alzheimer's disease. Maturitas 31, 185-200. doi: 10.1016/S0378-5122(98)00110-8

Rocchi, A., Pellegrini, S., Siciliano, G., and Murri, L. (2003). Causative and susceptibility genes for Alzheimer's disease: a review. Brain Res. Bull. 61, 1-24. doi: 10.1016/S0361-9230(03)00067-4

Rogers, J. T., and Lahiri, D. K. (2004). Metal and inflammatory targets for Alzheimer's disease. Curr. Drug Targets. 5, 535-551. doi: $10.2174 / 1389450043345272$

Roney, C. A., Arora, V., Kulkarni, P. V., Antich, P. P., and Bonte, F. J. (2009). Nanoparticulate radiolabelled quinolines detect amyloid plaques in mouse models of Alzheimer's disease. Int. J. Alzheimer's Dis. 2009:481031. doi: $10.4061 / 2009 / 481031$

Rowe, C. C., Ellis, K. A., Rimajova, M., Bourgeat, P., Pike, K. E., Jones, G., et al. (2010). Amyloid imaging results from the Australian imaging, biomarkers and lifestyle (AIBL) study of aging. Neurobiol. Aging 31, 1275-1283. doi: 10.1016/j.neurobiolaging.2010.04.007

Salek, R. M., Xia, J., Innes, A., Sweatman, B. C., Adalbert, R., Randle, S., et al. (2010). A metabolomic study of the CRND8 transgenic 
mouse model of Alzheimer's disease. Neurochem. Int. 56, 937-947. doi: 10.1016/j.neuint.2010.04.001

Santos, R. X., Correia, S. C., Wang, X., Perry, G., Smith, M. A., Moreira, P. I., et al. (2010). Alzheimer's disease: diverse aspects of mitochondrial malfunctioning. Int. J. Clin. Exp. Pathol. 3, 570-581.

Schrag, M., McAuley, G., Pomakian, J., Jiffry, A., Tung, S., Mueller, C., et al. (2010). Correlation of hypointensities in susceptibility-weighted images to tissue histology in dementia patients with cerebral amyloid angiopathy: a postmortem MRI study. Acta Neuropathol. 119, 291-302. doi: 10.1007/s00401-009-0615-Z

Scott, C. J. M., Szilagyi, G. M., Chavez, S., Ganda, A., and Black, S. E. (2011) Applications of Chemical Shift Imaging for AD. Curr. Med. Imaging Rev. 7, 88-95. doi: 10.2174/157340511794653513

Selkoe, D. J. (2008). Soluble oligomers of the amyloid beta-protein impair synaptic plasticity and behavior. Behav. Brain Res. 192, 106-113. doi 10.1016/j.bbr.2008.02.016

Shankar, G. M., Li, S., Mehta, T. H., Garcia-Munoz, A., Shepardson, N. E., Smith, I., et al. (2008). Amyloid-beta protein dimers isolated directly from Alzheimer's brains impair synaptic plasticity and memory. Nat. Med. 14, 837-842. doi: $10.1038 / \mathrm{nm} 1782$

Shin, J., Lee, S. Y., Kim, S. J., Kim, S. H., Cho, S. J., and Kim, Y. B. (2010). Voxel-based analysis of Alzheimer's disease PET imaging using a triplet of radiotracers: PIB, FDDNP, and FDG. Neuroimage 52, 488-496. doi: 10.1016/j.neuroimage.2010.04.013

Shin, J., Tsui, W., Li, Y., Lee, S. Y., Kim, S. J., Cho, S. J., et al. (2011). Restingstate glucose metabolism level is associated with the regional pattern of amyloid pathology in Alzheimers disease. Int. J. Alzheimer's Dis. 2011:759780. doi: $10.4061 / 2011 / 759780$

Sigurdsson, E. M., Wadghiri, Y. Z., Mosconi, L., Blind, J. A., Knudsen, E., Asuni, A., et al. (2008). A non-toxic ligand for voxel-based MRI analysis of plaques in AD transgenic mice. Neurobiol. Aging 29, 836-847. doi: 10.1016/j.neurobiolaging.2006.12.018

Small, G. W., Bookheimer, S. Y., Thompson, P. M., Cole, G. M., Huang, S. C., Kepe, V., et al. (2008). Current and future uses of neuroimaging for cognitively impaired patients. Lancet Neurol. 7, 161-172. doi: 10.1016/S14744422(08)70019-X

Sperling, R. A., Aisen, P. S., Beckett, L. A., Bennett, D. A., Craft, S., Fagan, A. M., et al. (2011). Toward defining the preclinical stages of Alzheimer's disease: recommendations from the national institute on Aging-Alzheimer's association workgroups on diagnostic guidelines for Alzheimer's disease. Alzheimer's Dement. 7, 280-292. doi: 10.1016/j.jalz.2011.03.003

Sperling, R. A., Dickerson, B. C., Pihlajamaki, M., Vannini, P., LaViolette, P. S., Vitolo, O. V., et al. (2010). Functional alterations in memory networks in early Alzheimer's disease. Neuromolecular Med. 12, 27-43. doi: 10.1007/s12017-0098109-7

Stebbins, G. T., and Murphy, C. M. (2009). Diffusion tensor imaging in Alzheimer's disease and mild cognitive impairment. Behav. Neurol. 21, 39-49. doi: $10.1155 / 2009 / 915041$

Strome, E. M., and Doudet, D. J. (2007). Animal models of neurodegenerative disease: insights from in vivo imaging studies. Mol. Imaging Biol. 9, 186-195. doi: 10.1007/s11307-007-0093-4

Sultana, R., Perluigi, M., and Butterfield, D. A. (2009). Oxidatively modified proteins in Alzheimer's disease (AD), mild cognitive impairment and animal models of AD: role of Abeta in pathogenesis. Acta Neuropathol. 118, 131-150. doi: 10.1007/s00401-009-0517-0

Teipel, S. J., Kaza, E., Hadlich, S., Bauer, A., Bruning, T., Plath, A. S., et al. (2011) Automated Detection of amyloid-beta-related cortical and subcortical signal changes in a transgenic model of Alzheimer's disease using high-field MRI. J. Alzheimers Dis. 23, 221-237. doi: 10.3233/JAD-2010-101035

Teng, E., Kepe, V., Frautschy, S. A., Liu, J., Satyamurthy, N., Yang, F., et al. (2011). [F-18]FDDNP microPET imaging correlates with brain Abeta burden in a transgenic rat model of Alzheimer disease: effects of aging, in vivo blockade, and anti-Abeta antibody treatment. Neurobiol. Dis. 43, 565-575. doi: 10.1016/j.nbd.2011.05.003

Thiessen, J. D., Glazner, K. A., Nafez, S., Schellenberg, A. E., Buist, R., Martin, M., et al. (2010). Histochemical visualization and diffusion MRI at 7 Tesla in the TgCRND8 transgenic model of Alzheimer's disease. Brain Struct. Funct. 215, 29-36. doi: 10.1007/s00429-010-0271-z

Toyama, H., Ye, D., Ichise, M., Liow, J. S., Cai, L., Jacobowitz, D., et al. (2005). PET imaging of brain with the beta-amyloid probe, [11C]6-OH-BTA-1, in a transgenic mouse model of Alzheimer's disease. Eur. J. Nucl. Med. Mol. Imaging 32, 593-600. doi: 10.1007/s00259-005-1780-5

Valla, J., Chen, K., Berndt, J. D., Gonzalez-Lima, F., Cherry, S. R., Games, D., et al. (2002). Effects of image resolution on autoradiographic measurements of posterior cingulate activity in PDAPP mice: implications for functional brain imaging studies of transgenic mouse models of Alzheimer's Disease. Neuroimage 16, 1-6. doi: 10.1006/nimg.2002.1080

Valla, J., Gonzalez-Lima, F., and Reiman, E. M. (2008). FDG autoradiography reveals developmental and pathological effects of mutant amyloid in PDAPP transgenic mice. Int. J. Dev. Neurosci. 26, 253-258. doi: 10.1016/j.ijdevneu.2008.02.003

Valla, J., Schneider, L., and Reiman, E. M. (2006). Age- and transgene-related changes in regional cerebral metabolism in PSAPP mice. Brain Res. 1116, 194-200. doi: 10.1016/j.brainres.2006.07.097

Vallabhajosula, S. (2011). Positron emission tomography radiopharmaceuticals for imaging brain Beta-amyloid. Semin. Nucl. Med. 41, 283-299. doi: 10.1053/j.semnuclmed.2011.02.005

van Gool, W. A., and Eikelenboom, P. (2000). The two faces of Alzheimer's disease J. Neurol. 247, 500-505. doi: 10.1007/s004150070147

Vanhoutte, G., Dewachter, I., Borghgraef, P., Van Leuven, F., and Van der Linden, A. (2005). Noninvasive in vivo MRI detection of neuritic plaques associated with iron in APP V717I transgenic mice, a model for Alzheimer's disease. Magn. Reson. Med. 53, 607-613. doi: 10.1002/mrm.20385

Vemuri, P., and Jack, C. R. Jr. (2010). Role of structural MRI in Alzheimer's disease Alzheimer's Res. Ther. 2, 23. doi: 10.1186/alzrt47

Versluis, M. J., Peeters, J. M., van Rooden, S., van der Grond, J., van Buchem, M. A., Webb, A. G., et al. (2010). Origin and reduction of motion and f0 artifacts in high resolution $\mathrm{T}-2^{*}$-weighted magnetic resonance imaging: application in Alzheimer's disease patients. Neuroimage 51, 1082-1088. doi: 10.1016/j.neuroimage.2010.03.048

Villemagne, V. L., Burnham, S., Bourgeat, P., Brown, B., Ellis, K. A., Salvado, O., et al. (2013). Amyloid beta deposition, neurodegeneration, and cognitive decline in sporadic Alzheimer's disease: a prospective cohort study. Lancet Neurol. 12, 357-367. doi: 10.1016/S1474-4422(13)70044-9

Villemagne, V. L., and Rowe, C. C. (2011). Amyloid imaging. Int. Psychogeriatr. 23(Suppl. 2), S41-S49. doi: 10.1017/S1041610211000895

von Kienlin, M., Kunnecke, B., Metzger, F., Steiner, G., Richards, J. G., Ozmen, L., et al. (2005). Altered metabolic profile in the frontal cortex of PS2APP transgenic mice, monitored throughout their life span. Neurobiol. Dis. 18, 32-39. doi: 10.1016/j.nbd.2004.09.005

Wadghiri, Y. Z., Sigurdsson, E. M., Sadowski, M., Elliott, J. I., Li, Y., Scholtzova, H., et al. (2003). Detection of Alzheimer's amyloid in transgenic mice using magnetic resonance microimaging. Magn. Reson. Med. 50, 293-302. doi: 10.1002/mrm. 10529

Waerzeggers, Y., Monfared, P., Viel, T., Winkeler, A., and Jacobs, A. H. (2010) Mouse models in neurological disorders: applications of non-invasive imaging. Biochim. Biophys. Acta 802, 819-839. doi: 10.1016/j.bbadis.2010.04.009

Wengenack, T. M., Jack, C. R. Jr., Garwood, M., and Poduslo, J. F. (2008). MR microimaging of amyloid plaques in Alzheimer's disease transgenic mice. Eur. J. Nucl. Med. Mol. Imaging 35(Suppl. 1), S82-S88. doi: 10.1007/s00259-007-0706

Wengenack, T. M., Reyes, D. A., Curran, G. L., Borowski, B. J., Lin, J., Preboske, G. M., et al. (2011). Regional differences in MRI detection of amyloid plaques in AD transgenic mouse brain. Neuroimage 54, 113-122. doi: 10.1016/j.neuroimage.2010.08.033

Westman, E., Wahlund, L. O., Foy, C., Poppe, M., Cooper, A., Murphy, D., et al. (2011). Magnetic resonance imaging and magnetic resonance spectroscopy for detection of early Alzheimer's disease. J. Alzheimer's Dis. 26(Suppl. 3), 307-319. doi: 10.3233/JAD-2011-0028

Wisniewski, T., and Sigurdsson, E. M. (2010). Murine models of Alzheimer's disease and their use in developing immunotherapies. Biochim. Biophys. Acta-Mol. Basis Dis. 1802, 847-859. doi: 10.1016/j.bbadis.2010.05.004

Woodhouse, A., Vickers, J. C., Adlard, P. A., and Dickson, T. C. (2009). Dystrophic neurites in TgCRND8 and Tg2576 mice mimic human pathological brain aging. Neurobiol. Aging 30, 864-874. doi: 10.1016/j.neurobiolaging.2007.09.003

Wu, W., and Small, S. A. (2006). Imaging the earliest stages of Alzheimer's disease. Curr. Alzheimer Res. 3, 529-539. doi: 10.2174/156720506779025161

Xu, W., Zhan, Y., Huang, W., Wang, X., Zhang, S., and Lei, H. (2010). Reduction of hippocampal $\mathrm{N}$-acetyl aspartate level in aged $\mathrm{APP}(\mathrm{Swe}) / \mathrm{PS} 1(\mathrm{dE} 9)$ transgenic 
mice is associated with degeneration of CA3 pyramidal neurons. J. Neurosci. Res. 88, 3155-3160. doi: 10.1002/jnr.22479

Yakushev, I., Gerhard, A., Muller, M. J., Lorscheider, M., Buchholz, H. G., Schermuly, I., et al. (2011a). Relationships between hippocampal microstructure, metabolism, and function in early Alzheimer's disease. Brain Struct. Funct. 216, 219-226. doi: 10.1007/s00429-011-0302-4

Yakushev, I., Schreckenberger, M., Muller, M. J., Schermuly, I., Cumming, P., Stoeter, P., et al. (2011b). Functional implications of hippocampal degeneration in early Alzheimer's disease: a combined DTI and PET study. Eur. J. Nucl. Med. Mol. Imaging 38, 2219-2227. doi: 10.1007/s00259-011-1882-1

Yanagisawa, D., Amatsubo, T., Morikawa, S., Taguchi, H., Urushitani, M., Shirai, $\mathrm{N}$., et al. (2011). In vivo detection of amyloid beta deposition using (1)F magnetic resonance imaging with a (1)F-containing curcumin derivative in a mouse model of Alzheimer's disease. Neuroscience 184, 120-127. doi: 10.1016/j.neuroscience.2011.03.071

Yang, J., Wadghiri, Y. Z., Hoang, D. M., Tsui, W., Sun, Y. J., Chung, E., et al. (2011) Detection of amyloid plaques targeted by USPIO-A beta 1-42 in Alzheimer's disease transgenic mice using magnetic resonance microimaging. Neuroimage 55, 1600-1609. doi: 10.1016/j.neuroimage.2011.01.023

Ye, L., Morgenstern, J. L., Lamb, J. R., and Lockhart, A. (2006). Characterisation of the binding of amyloid imaging tracers to rodent Abeta fibrils and rodenthuman Abeta co-polymers. Biochem. Biophys. Res. Commun. 347, 669-677. doi: 10.1016/j.bbrc.2006.06.126

Yousefi, B. H., Manook, A., Drzezga, A., von Reutern, B., Schwaiger, M., Wester, H. J., et al. (2011). Synthesis and evaluation of 11C-labeled imidazo[2,1-b]benzothiazoles (IBTs) as PET tracers for imaging beta-amyloid plaques in Alzheimer's disease. J. Med. Chem. 54, 949-956. doi: 10.1021/jm $101129 \mathrm{a}$
Zahs, K. R., and Ashe, K. H. (2010). “Too much good news” - are Alzheimer mouse models trying to tell us how to prevent, not cure, Alzheimer's disease? Trends Neurosci. 33, 381-389. doi: 10.1016/j.tins.2010.05.004

Zetzsche, T., Rujescu, D., Hardy, J., and Hampel, H. (2010). Advances and perspectives from genetic research: development of biological markers in Alzheimer's disease. Expert Rev. Mol. Diagn. 10, 667-690. doi: 10.1586/erm.10.48

Zhang, J., Yarowsky, P., Gordon, M. N., Di Carlo, G., Munireddy, S., van Zijl, P. C., et al. (2004). Detection of amyloid plaques in mouse models of Alzheimer's disease by magnetic resonance imaging. Magn. Reson. Med. 51, 452-457. doi: 10.1002/mrm. 10730

Conflict of Interest Statement: The authors declare that the research was conducted in the absence of any commercial or financial relationships that could be construed as a potential conflict of interest.

Received: 12 June 2014; accepted: 27 September 2014; published online: 31 October 2014.

Citation: Adlard PA, Tran BA, Finkelstein DI, Desmond PM, Johnston LA, Bush AI and Egan GF (2014) A review of $\beta$-amyloid neuroimaging in Alzheimer's disease. Front. Neurosci. 8:327. doi: 10.3389/fnins.2014.00327

This article was submitted to Brain Imaging Methods, a section of the journal Frontiers in Neuroscience.

Copyright (C) 2014 Adlard, Tran, Finkelstein, Desmond, Johnston, Bush and Egan. This is an open-access article distributed under the terms of the Creative Commons Attribution License (CC BY). The use, distribution or reproduction in other forums is permitted, provided the original author(s) or licensor are credited and that the original publication in this journal is cited, in accordance with accepted academic practice. No use, distribution or reproduction is permitted which does not comply with these terms. 